\title{
Identifying the Effects of Government Spending Shocks with and without Expected Reversal: An Approach Based on U.S. Real-Time Data
}

\author{
Jacopo Cimadomo \\ Sebastian Hauptmeier \\ Sergio Sola \\ Graduate Institute of International Studies
}

European Central Bank, Directorate General Economics, Fiscal Policies Division

European Central Bank, Directorate General Economics, Fiscal Policies Division

\begin{abstract}
This paper investigates how expectations about future government spending affect the transmission of fiscal policy shocks. We study the effects of two different types of government spending shocks in the United States: (i) spending shocks that are accompanied by an expected reversal of public spending growth below trend; (ii) spending shocks that are accompanied by expectations of future spending growth above trend. We use the Ramey (2011)'s time series of military build-ups to measure exogenous spending shocks, and deviations of forecasts of public spending with respect to past trends, evaluated in real-time, to distinguish shocks into these two categories. Based on a structural VAR analysis, our results suggest that shocks associated with an expected spending reversal exert expansionary effects on the economy and accelerate the correction of the initial increase in public debt. Shocks associated with expected spending growth above trend, instead, are characterized by a contraction in aggregate demand and a more persistent increase in public debt. The main channel of transmission seems to run through agents' perception of the future macroeconomic environment.
\end{abstract}

(C) The Authors.

All rights reserved. No part of this paper may be reproduced without the permission of the authors. 


\title{
Identifying the Effects of Government Spending Shocks with and without Expected Reversal: an Approach Based on U.S. Real-Time Data*
}

\author{
Jacopo Cimadomo $\quad$ Sebastian Hauptmeier* Sergio Sola ${ }^{\star}$
}

June 2011

\begin{abstract}
This paper investigates how expectations about future government spending affect the transmission of fiscal policy shocks. We study the effects of two different types of government spending shocks in the United States: (i) spending shocks that are accompanied by an expected reversal of public spending growth below trend; (ii) spending shocks that are accompanied by expectations of future spending growth above trend. We use the Ramey (2011)'s time series of military build-ups to measure exogenous spending shocks, and deviations of forecasts of public spending with respect to past trends, evaluated in real-time, to distinguish shocks into these two categories. Based on a structural VAR analysis, our results suggest that shocks associated with an expected spending reversal exert expansionary effects on the economy and accelerate the correction of the initial increase in public debt. Shocks associated with expected spending growth above trend, instead, are characterized by a contraction in aggregate demand and a more persistent increase in public debt. The main channel of transmission seems to run through agents' perception of the future macroeconomic environment.
\end{abstract}

JEL: E62, E65, H20.

Keywords: Government spending shocks, Survey of Professional Forecasters, Real-time data, Spending reversal, Fiscal multipliers.

\footnotetext{
"We would like to thank the participants to an ECB seminar, to the International Conference on Macroeconomic Analysis and International Finance and to the North American Summer Meeting of the Econometric Society, for useful comments and discussions. In particular, we would like to thank Gianni Amisano, Agnès Bénassy-Quéré, Stephan Fahr, Davide Furceri, Massimo Giuliodori, Michele Lenza, Philipp Rother, Ad van Riet and Charles Wyplosz. Sergio Sola gratefully acknowledges the Fiscal Policies Division of the ECB for its hospitality. The opinions expressed herein are those of the authors and do not necessarily reflect those of the ECB or the Eurosystem.

- European Central Bank, Directorate General Economics, Fiscal Policies Division, Kaiserstraße 29, D60311 Frankfurt am Main, Germany, E-mail: jacopo.cimadomo@ecb.europa.eu.

* European Central Bank, Directorate General Economics, Fiscal Policies Division, Kaiserstraße 29, D60311 Frankfurt am Main, Germany, E-mail: sebastian.hauptmeier@ecb.europa.eu.

- Graduate Institute of International Studies, Department of Economics, 11A Avenue de La Paix, 1201 Genève, Switzerland, E-mail: sergio.sola@graduateinstitute.ch
} 


\section{Contents}

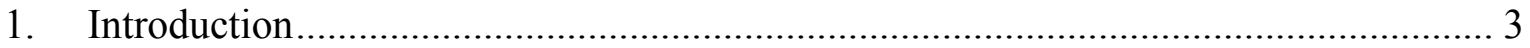

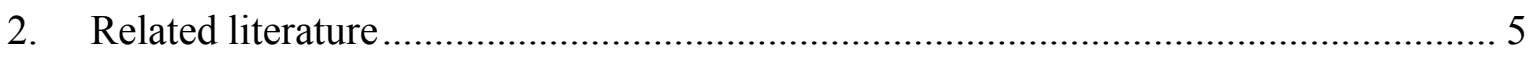

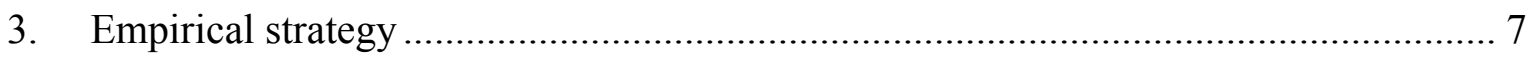

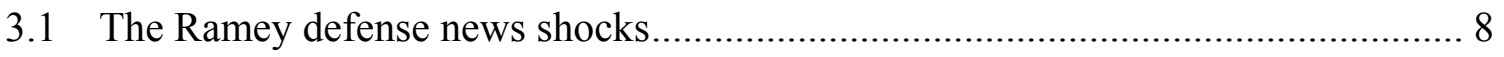

3.2 Identifying shocks with and without expected reversal ...................................... 9

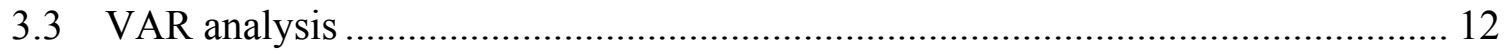

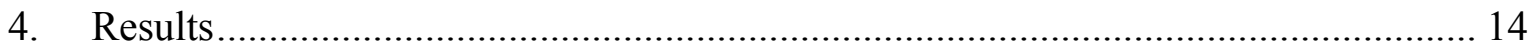

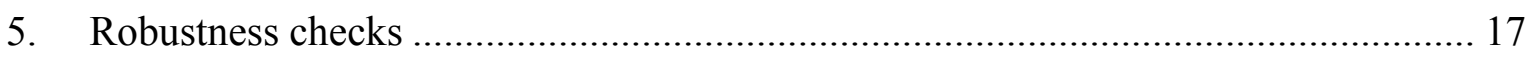

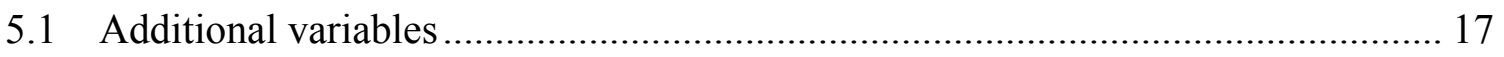

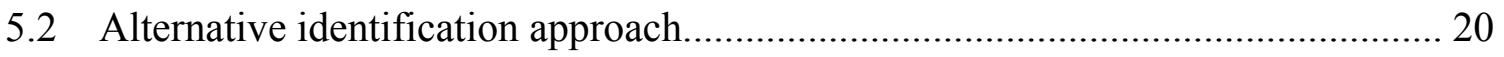

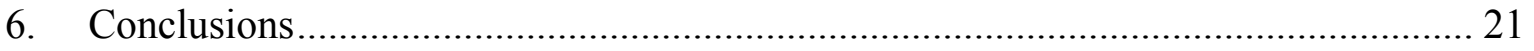

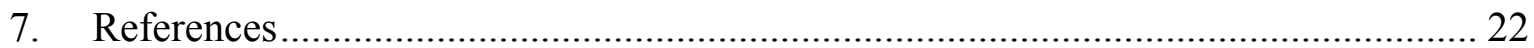

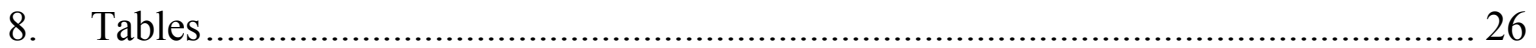

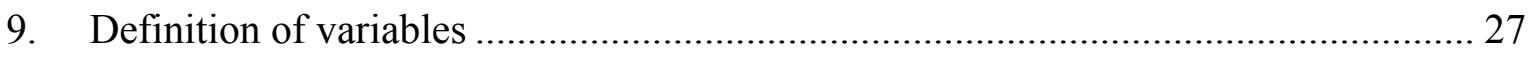

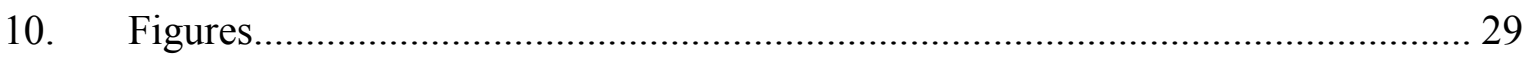




\section{Introduction}

The global financial and economic crisis of 2008 and 2009 has induced governments in most industrialized countries to make extensive use of discretionary, in particular spending-based, fiscal policy measures to counteract the economic downturn. While these measures are argued to have averted an even more severe economic contraction, uncertainties regarding the macroeconomic effects of discretionary fiscal policies remain. At the same time, the adoption of fiscal stimulus packages, together with the automatic reaction of government deficits to the economic slowdown, has certainly contributed to the strong increase in public debt-to-GDP ratios in most countries. These developments have motivated a lively debate among academics and policy makers on the effectiveness of fiscal policies in stimulating economic activity (i.e. on the sign and the size of fiscal policy multipliers), and on the costs of expansionary fiscal policies in terms of public debt accumulation and risks to the long-term sustainability of public finances.

The theoretical literature suggests that fiscal policy multipliers depend on a wide range of factors such as the monetary policy stance, the exchange rate regime, the degree of capital markets integration and credit market frictions as well as agents' expectations about the future path of fiscal policy. The latter were already contemplated by early Real Business Cycle models (see e.g. Baxter and King, 1993) according to which fiscal expansions can produce a negative response in private consumption given that they are expected to increase the future tax burden. Only recently, some studies use (calibrated) NewKeynesian DGSE models to address explicitly the interplay between fiscal policy and management of expectations as a key factor to understand the transmission mechanisms of fiscal policy. In particular, Davig and Leeper (2011) show that the effects of fiscal policy shocks depend on the future path of monetary and fiscal policy and on the interaction between them. Corsetti et al. $(2009,2010)$ highlight that the size of multipliers depends on whether the government will offset the shock with higher future taxes or rather with lower future spending. They find that government spending multipliers are considerably larger when fiscal shocks are accompanied by a future reduction in spending. By granting a central role to the future paths of fiscal policy variables, these papers represent a big step forward in the understanding of the size and the sign of fiscal policy multipliers.

Against this background, the goal of this paper is to test empirically the predictions of this class of models based on a new approach that explicitly takes into consideration - in an otherwise standard VAR model for fiscal policy analysis - agents' expectations about the 
future fiscal policy stance after a fiscal policy shock. In particular, we investigate whether expectations about future government spending growth are relevant for explaining the effectiveness of fiscal policy shocks and the evolution of public debt following fiscal expansions.

Focusing on the United States and on a quarterly dataset spanning the period 1981Q32008Q3, our empirical strategy consists of three steps. First, we collect the fiscal shocks on military expenditure (i.e. the so-called "defense news" shocks) estimated and reported by Ramey (2011). These shocks, constructed following a "narrative" approach, can reasonably be considered to be truly "exogenous" and "unsystematic" and therefore should be immune to the 'Fiscal Foresight' Critique (see Leeper, Walker and Yang, 2009). Second, we propose a new identification procedure which combines the Ramey shocks with information on forecasts of future government spending as well as on past spending trends available "in real time" when the shock occurred. As a proxy for agents" expectations about future government spending growth, we use projections on government consumption and investment spending reported in the Survey of Professional Forecasters and published by the Federal Reserve Bank of Philadelphia. Trends for past spending growth and for the same spending aggregate are constructed from past vintages of realtime data also from the Philadelphia Fed database. Based on these data, we are able to divide the Ramey shocks into two categories, i.e. one including shocks associated with expectations of a future reversal in government expenditures and the other including shocks that are not associated with such reversal. More specifically, we define: (i) spending shocks with an expected reversal as those positive shocks for which, at the time they occur, expected spending growth at the one-year-ahead horizon is below a long-run historical trend for spending growth; (ii) spending shocks with no expected reversal as those positive shocks for which spending growth expected for the next year is above past spending growth, over the same long-run period. ${ }^{1}$ Third, we incorporate these two types of shocks in a structural VAR model, including also GDP, private consumption and investment, and public debt among other variables, to investigate the differences in the responses of the economy.

To the best of our knowledge, this is the first paper that considers agents' expectations about future government spending, in combination with past vintages of real-time data, to

\footnotetext{
${ }^{1}$ As discussed below, the category of spending shocks with expected reversal also includes negative defense news shocks, accompanied by projections on spending growth below above past trends of spending growth. Moreover, the category of spending shocks without expected reversal also includes negative defense news shocks, accompanied by projections on spending growth below above past trends of spending growth.
} 
analyze the effects of different types of government spending shocks. Compared to VAR analysis proposed by Corsetti et al. (2009), our approach allows us to estimate the effects of government spending shocks that are followed by a reversal in spending growth and of shocks that are followed by a further increase in spending growth.

Our results suggest that expectations indeed matter for the effects of fiscal policy shocks and the evolution of public debt. We find that fiscal shocks that are followed by an expected reversal in spending have a positive effect on aggregate demand. In addition, they are associated with an increase in public debt for about one year. After that, public debt declines, following the automatic reaction of the budget balance to the economic expansion induced by the fiscal shock. At the same time, it emerges that fiscal shocks characterized by expectations of further increases of public spending are associated with a reduction in economic activity (especially in the short-run) and with a more persistent increase in public debt. The latter tends to remain above its initial level over the whole considered horizon. These effects seem to run mostly through the reaction of consumers' confidence about the future macroeconomic environment, which is also reflected in a flatter slope of the yield curve in the case of shocks with reversal.

The rest of this paper is organized as follows. In Section 2, we summarize the related literature on fiscal policy multipliers; section 3 presents the empirical strategy and the identification of fiscal shocks; in section 4 we report and comment the results. Finally, in section 5 several robustness checks are discussed and section 6 concludes.

\section{Related literature}

It is by now relatively well established in the empirical literature that fiscal policy multipliers vary across countries and across time (for a review, see e.g. Spilimbergo et al., 2009), depending on a wide range of factors (see e.g. Kirchner, Cimadomo and Hauptmeier, 2010). The impact of some of these factors (notably, the exchange rate regime, the composition of public spending, the monetary policy stance, the state of the business cycle) on the effectiveness of fiscal policy has already been explored quite extensively in the empirical literature.

For example, Ilzetzki, Mendoza and Vegh (2009), show that - across a wide panel of countries - the effects of fiscal policy broadly reflect the prediction of the Mundell- 
Fleming model in that economies operating under predetermined exchange rate regimes tend to have higher fiscal multipliers than the ones operating under flexible exchange rate regimes. Beetsma and Giuliodori (2011) document that, at the EU level, the effects of government spending shocks on the economy are more sizeable for relatively closed economies, than for open ones. Focusing on Ireland, Bénétrix and Lane (2009) highlight that the impact of government spending shocks on the level and composition of output may depend on the nature of the fiscal innovation. In particular, shocks to public investment have more sizeable effects than shocks to government consumption. At the same time, Furceri and Zdzienicka (2011) find that social spending may also have a positive and sizeable effect on GDP. The relation between the stance of monetary policy and the effectiveness of fiscal policy has been inspected by Kirchner, Cimadomo and Hauptmeier (2010) for the euro area, and by Canova and Pappa (2011) for a larger set of countries. The former paper shows that fiscal policy became less powerful since the end of the 1990s in the euro area, also as a consequence of a more forceful response of monetary policy to fiscal expansions. Canova and Pappa (2011) find that an accommodative stance of monetary policy leads to large output multipliers in normal times in the euro area, the US and the UK. The interlink between the state of the business cycle and fiscal policy effectiveness has been investigated by Tagkalakis (2008) and Hemming, Mahfouz and Schimmelpfenning (2002) who highlight that fiscal policy tends to be more powerful in recessions, given the prevalence of credit constrained households in this phase of the economic cycle. In fact, whenever agents are excluded from credit markets, they cannot smooth consumption and therefore any increase in disposable income is readily transformed into an increase in current consumption. Perotti (2005) also argues that progressively relaxed credit constraints over the last decades contributed to explain falling fiscal policy multipliers (see also Gali, Lopez-Salido and Vellès, 2007; and Bilbiie, Meier and Muller, 2008).

At the same time, the interplay between agents' expectations and the effects of fiscal policy has thus far received only limited attention in empirical work. As discussed above, agents' expectations about the future fiscal policy stance may clearly play a role in today's investment and consumption decisions by forward-looking agent as suggested by Corsetti et al. (2009), Davig and Leeper (2011). Early attempts to test - at least indirectly - this channel of transmission have been made in the 1990s by authors exploring so-called nonKeynesian effects of fiscal policy. Such effects would emerge if fiscal consolidations trigger expectations of lower future interest rates and inflation, and therefore stimulate 
economic activity even on impact (see, in particular, Giavazzi and Pagano 1990, 1996). This mechanism has been shown to be particularly strong when the level of public debt is high as under such circumstances consolidations are likely to induce agents to reduce precautionary savings and increase consumption (see e.g. Giavazzi, Jappelli, Pagano, 2000; Berben and Brosens, 2007). ${ }^{2}$ These papers, while clearly assigning an important role to expectations, do not explicitly incorporate measures of expectations into their empirical models. $^{3}$

The interaction between agents' expectations and the effectiveness of fiscal policy has been addressed by Corsetti et al. (2009) using a calibrated DSGE model for the US economy. Their analysis shows that fiscal multipliers vary depending on whether the fiscal expansion is accompanied by a credible plan of future reduction in public spending. Expected future real interest rates decrease in presence of credible retrenchment of future spending which directly feeds into today's long term real interest rates and in turn boosts consumption and output. However, the empirical (VAR-based) analysis presented in Corsetti et al. (2009) does not incorporate directly measures of expectations. In addition, the effects of shocks without a spending reversal is not explored in their framework.

Against this background, in this paper we incorporate agents' expectations regarding a possible spending reversal in a VAR model for fiscal policy analysis. ${ }^{4}$ This allows us to estimate the effects of shocks with and without expected reversals. In addition, some key channels through which expected future consolidations can influence the effectiveness of fiscal policy are investigated.

\section{Empirical strategy}

We focus on the US economy over the period 1981:Q3 - 2008:Q3. Our empirical analysis consists of three steps. First, we collect the "defense news" shocks reported by Ramey (2011). Second, we propose a new identification procedure which combines the Ramey shocks with information available "in real time" on historical and projected government

\footnotetext{
${ }^{2}$ On non-Keynesian effects of fiscal policy, see also Alesina and Perotti (1997), Alesina and Ardagna (1998), Perotti (1999), Ardagna (2004), Afonso (2010).

${ }^{3}$ Wyplosz (2005) also argues that the effectiveness fiscal policies will depend on how agents perceive the future fiscal policy stance and on how credible are fiscal institutions to ensure the long-term sustainability of public finances. In our paper, we propose an approach that explicitly takes into account the role of private sector expectations in shaping the fiscal transmission mechanism.

${ }^{4}$ Other attempts to incorporate expectations on government spending growth in VAR models, based on projections reported in the Survey of Professional Forecasters, are Kirchner (2010), Aureback and Gorodnichenko (2010). However, these papers utilize expectations with a different purpose, namely to address the 'Fiscal Foresight' critique put forward by Leeper Walker and Yang (2009).
} 
spending trends. This enables us to distinguish two types of spending shocks, i.e. shocks that are accompanied by the expectation of future spending reversal (to growth rates below a historical trend) and shocks that are not. Third, we incorporate these two classes of shocks in an otherwise standard structural VAR model. This allows us to trace the effects of these two types of fiscal shocks on the economy.

\subsection{The Ramey defense news shocks}

As a first step in the empirical analysis we need to select some government spending shocks which can reasonably be considered to be exogenous to business cycle fluctuations, and unpredictable on the basis of ex-ante information held by agents. Natural candidates are the "defense news" shocks constructed by Ramey (2011) on the basis of a "narrative approach". In particular, Ramey (2011) refines the standard Ramey and Shapiro (1998) "war dates" approach by constructing a new variable of discretionary government spending shocks. As in Romer and Romer (2010), information from the press (mainly Business Week) is used to build a historical series of expected changes in government military spending which then are expressed in present value terms. This offers a number of advantages: First, the construction of the variable is transparent and has been thoroughly documented by the author (see Ramey, 2009) ${ }^{6}$. Second, data are reported at the quarterly frequency and are characterized by a relatively large number of observations, e.g. compared to the "traditional" narrative approach which is based on only few dummies for war dates (see Ramey and Shapiro, 1998). Third, the use of fiscal "news" ensures that the shocks are identified before the spending actually takes place. This helps to reduce the risk of endogeneity problems in the VAR analysis related to the presence of "fiscal foresight", i.e. the possibility that lags between the planning and the implementation stage of fiscal policy lead to an anticipation of spending shocks (see Leeper, Walker and Yang, 2009). ${ }^{7}$ The decision to consider only military spending can be justified by the fact that, as pointed out by Ramey (2011), defense spending accounts for the bulk of variation in government expenditure in the US. The Ramey shocks for the period under consideration

\footnotetext{
${ }^{5}$ See also Ramey (2009) for a detailed documentation on the construction of such shocks. Earlier works based on a narrative approach for fiscal policy analysis are Ramey and Shapiro (1998), Edelberg, Eichenbaum and Fisher (1999).

${ }^{6}$ Further documentation is available on V. Ramey's webpage: http://weber.ucsd.edu/ vramey/published.html ${ }^{7}$ See also Forni and Gambetti (2010) for an alternative method to address the fiscal foresight critique, based on a structural factor model approach.
} 
are reported in column 2 and 3 of table 1, both in nominal terms and in percent of previous quarter GDP. ${ }^{8}$

\subsection{Identifying shocks with and without expected reversal}

As a second step in our identification strategy, we look at the path of future spending growth expected at the time (quarter) each Ramey shock occurred. We compare this path with past trends in government spending growth, again evaluated at the time each defense news shock took place. For this purpose we use vintages of real-time data on government spending released in the respective quarter. This procedure allows us to distinguish two types of Ramey shocks: ${ }^{9}$

(i) Shocks with an expected reversal in government expenditure: this category comprises positive defense news shocks, which are accompanied by projections on spending growth below past trends of spending growth. This category also includes negative defense news shocks, accompanied by projections on spending growth above past trends of spending growth.

(ii) Shocks without an expected reversal in government expenditure: this category comprises positive defense news shocks, which are accompanied by projections on spending growth above past trends of spending growth. This category also includes negative defense news shocks, accompanied by projections on spending growth below past trends of spending growth.

To proxy agents' expectations about future government spending growth, we use projections reported in Survey of Professional Forecasters (SPF) published by the Philadelphia Fed. ${ }^{10}$ The SPF reports forecasts for an ample set of macroeconomic and financial variables on a quarterly basis, including projections on government consumption and investment. While the Ramey shocks are based only on military expenditure, we use projections for the largest available aggregate for government spending, comprising government consumption and investment at the federal, state and local level, to evaluate

\footnotetext{
${ }^{8}$ Data in table 1 are taken from table 2 in Ramey (2011).

${ }^{9}$ Note that also Corsetti et al. (2009) evaluate reversal with respect to trends. However, their empirical analysis is based on ex-post (revised) data and does not disentangle the two different types of shocks.

${ }^{10} \mathrm{See}$ http://www.philadelphiafed.org/research-and-data/real-time-center/survey-of-professional-forecasters/
} 
reversals. In fact, if expectations about future government spending are relevant in shaping today's decisions by agents then what matters are projections on overall spending rather than only on military expenses as these might be offset by other items in the future. In addition, this choice can be justified by the fact that the SPF comprises forecasts for the aggregates of government consumption and investment, but not forecasts for subcategories of spending such as military spending.

In the SPF, forecasts for government consumption and investments are expressed in real terms and seasonally adjusted at annual rates.

For our purpose, expected expenditure growth is computed as the annual growth rate between the current year estimate and the following year forecast, as projected in the quarter the defense news shock took place. ${ }^{11}$ The collection of SPF forecasts start from 1981Q3 and forecasts are at most for the one-year-ahead horizon. While ideally one would prefer to use forecasts for a longer horizon, we are restricted by data availability in the SPF. However, the one-year-ahead forecast already takes into account the full information set available at time $t$. This implies that the (average) annual expected growth rate for longer horizons (e.g. two or three years ahead) is expected to be close to the projected one-year-ahead growth rate, given that information for budgetary measures for two years ahead (or beyond) is typically not available.

We also control for the timing of the SPF compared to the timing of the Ramey shocks: agents should form expectations after the occurrence of the defense news shock, so that their consumption and investment decisions are affected by the exogenous shock and the expectation about future spending, incorporating the shock itself. In practice, projections from the SPF are based on questionnaires which are sent out to individual participants in the first week of each quarter. The responses are then sent back to the Philadelphia Fed by the third week of the second month of each quarter and are often received in the last day of this week. Hence, using the detailed information provided by Ramey (2009), we check the exact timing of each defense news shock and compare it with the timing of the SPF released in the quarter in which shocks occurred. The results are reported in Appendix B. Of the total of 17 shocks, 4 of them take place after the collection of forecasts for the relevant quarter. Hence, for these shocks, when assessing whether they are "with" or

\footnotetext{
${ }^{11}$ Concretely, the SPF reports a total of 8 projections for each variable (in levels), including the "backcast" for the spending for the previous quarter, the "nowcast" of spending for the present quarter and the forecasts for the following 4 quarters. All these are values are annualized and seasonally adjusted. Finally, the SPF reports the current and the one-year-ahead annual forecast. These are used in the context of our identification strategy.
} 
"without" expected reversal, we compare the past growth rate of government spending with expected spending growth measured in the quarter following the defense news shock. Thereby we ensure that the information set available to the questionnaire participants when forming their expectations about future spending growth includes the shock under consideration.

Past growth rates of public spending are computed using real-time data taken from the Philadelphia Fed's database as well. ${ }^{12}$ Again, the spending aggregate comprises government consumption and investment at the federal, state and local level. For a given news shock taking place in quarter $t$ of year $T$ we select a horizon of $h$ years and compute the average annual growth rate of public spending between $T$ and $T-h$ using the vintage for the real time data which refers to period $t$. To avoid that the results are driven by abnormal spikes in government spending growth we pass the series of real time data through a Hodrick-Prescott filter.

Using real-time data is important to approximate the information set of agents at the point in time when the defense news shock occurred. The intuition behind this approach is that agents, when evaluating whether future spending will grow more or less than in the past, will most likely draw from their experience about the "historical" path of government spending growth up to that point, which is exactly the type of information collected in real time vintages. In the baseline exercise we focus on a period of 15 years, which should be sufficiently long to capture historical growth trends in spending. At the same time, by restricting the assessment period to the previous 15 years we avoid the use of vintages at from the early 1980s which include the Korean war, a period characterized by very high government spending volatility. ${ }^{13}$

In sum, the distinction of the Ramey's defense shocks in the two categories "with" and "without" expected reversal follows this simple decision rule:

\begin{tabular}{l|l|l}
\hline \hline Positive Defense News Shocks & $\begin{array}{l}\Delta \mathrm{g}_{\mathrm{t}}^{\mathrm{e}}>\Delta \mathrm{g}_{\mathrm{t}, \mathrm{t}-15} \\
\Delta \mathrm{g}_{\mathrm{t}}^{\mathrm{e}}<\Delta \mathrm{g}_{\mathrm{t}, \mathrm{t}-15}\end{array}$ & $\begin{array}{l}\text { Shock Without Reversal } \\
\text { Shock With Reversal }\end{array}$ \\
\hline Negative Defense News Shocks & $\Delta \mathrm{g}_{\mathrm{t}}^{\mathrm{e}}>\Delta \mathrm{g}_{\mathrm{t}, \mathrm{t}-15}$ & Shock With Reversal \\
& $\Delta \mathrm{g}_{\mathrm{t}}{ }^{\mathrm{e}}<\Delta \mathrm{g}_{\mathrm{t}, \mathrm{t}-15}$ & Shock Without Reversal \\
\hline \hline
\end{tabular}

\footnotetext{
${ }^{12}$ See http://www.philadelphiafed.org/research-and-data/real-time-center/real-time-data/.

${ }^{13}$ Still, the robustness section 5 shows that results based on the 15-years horizon are broadly consistent a longer time horizon, based on a 25 -years window.
} 
where $\Delta \mathrm{g}_{\mathrm{t}}{ }^{\mathrm{e}}$ is the one-year-ahead expectation on spending growth, and $\Delta \mathrm{g}_{\mathrm{t}, \mathrm{t}-15}$ is spending growth for the previous 15 years evaluated in real-time on the basis of information available at the time of the Ramey's shock. This identification scheme allows us to capture the idea that agents react to news and their reaction tends to be driven by the shock itself as well as by their expectations about future spending relative to "historical" spending trends. As discussed, due to data availability, our sample covers the interval 1981Q3 through 2008Q3. Over this period we observe 17 Ramey defense news shocks. ${ }^{14}$ In column 3 of Table 1 the classification ("with reversal" or "no reversal") of each shock is reported. Tables 2, 3 and 4 show some descriptive statistics for the shocks. According to table 2 , out of the total of 17 shocks, 6 are identified as "with reversal" and 11 as "without reversal". The division of shocks in the two categories is more even if we look at positive shocks, while for negative shocks only 1 is reversed and 7 are not. Moreover the negative shocks are in general larger in size, as indicated in table 3. The average size of a fiscal consolidation is in fact $3.82 \%$ of previous quarter's GDP, compared with $1.41 \%$ of GDP for fiscal expansions. Finally, table 4 shows that shocks without reversal tend to be larger and more volatile than shocks with reversal for both positive and negative

\subsection{VAR analysis}

After dividing the defense news shocks into the two different categories we incorporate them as endogenous variables into a standard VAR model. ${ }^{15}$ The baseline VAR includes the two series of defense news shocks (with and without reversal), public debt, GDP, private consumption, private non-residential investment, the one-year-ahead expected inflation and the federal funds rate. All the data are expressed in real per capita terms except for the defense news shocks which are expressed in percentage of previous quarter GDP. Expected inflation and the federal fund rate are expressed in percentage points on annualized basis.

The inclusion of public debt owes to our aim to analyze the consequences of different fiscal policy shocks for debt accumulation, in addition to studying the size of fiscal multipliers. In fact, a fiscal shock that has strong positive effect on output can work in favour of reducing the stock of public debt by increasing tax revenues through the

\footnotetext{
${ }^{14}$ The fact that the SPF starts only in 1982 prevents to exploit the whole time series of the Ramey shocks. At the same time, the number of shocks included in our paper is well above the number of shocks used by other papers based on the narrative approach. For instance, Ramey and Shapiro (1998) use only four dummies of war dates.

${ }^{15}$ This approach follows Ramey (2010), who however did not separate the shocks into two categories.
} 
operation of automatic stabilizers, the so-called "growth dividend". Moreover, some papers have shown that omitting public debt from VAR models of fiscal policy may lead to substantial bias in the estimated responses to government spending shocks (see, e.g., Favero and Giavazzi, 2007). We use expected inflation rather than actual inflation as this is consistent with the fact that our shocks are "news shocks" and hence are more likely to affect directly the expectations of future prices rather than actual prices. Finally, we add the federal fund rate to take into account the reaction of monetary policy to fiscal shocks. The VAR also includes a constant and a quadratic trend. We incorporate four lags of the endogenous variables, given the quarterly nature of the series used. The VAR includes variables in levels, and it is estimated by OLS.

The identification of the fiscal shocks is achieved by means of a standard Cholesky decomposition, in a VAR where the defense news shocks are ordered first. This recursive structure and the selected ordering are justified by the fact that, by construction, the defense news shocks should be exogenous and independent to business cycle fluctuations and other endogenous variables. Therefore, the fiscal shocks need to be ordered first given that they should not react to shocks to other variables in the same quarter. ${ }^{16}$ Moreover, because we only identify innovations to the first two variables in the VAR, the relative ordering of the remaining variables will not alter the results (on this point, see Christiano, Eichembaum and Evans, 1999). In fact, only the relative position of shocks with reversal and shocks without reversal can impact on the results. However, robustness section 5 shows that changing the order of the two shocks does not significantly affect the results.

The data on GDP, consumption and investments are taken from the US Bureau of Economic Analysis's NIPA tables and the data on government debt from the ECB's Statistical Data Warehouse. The series of the one-year-ahead expected inflation is from the SPF and the data on the federal fund rate are taken from the New York Fed database. More details on the variables are reported in the Appendix.

\footnotetext{
${ }^{16}$ This is also in line with Fatàs and Mihov (2001) and Biilbie Meier Muller (2008), who adopt an identification scheme where government spending is ordered before output, following the assumption that government spending cannot react to output movements within the same quarter. Other approaches to identification for fiscal policy shocks are proposed by Blanchard and Perotti (2002) and Perotti (2005), based on "institutional'information"; and by Mountford and Uhlig (2009), based on sign restrictions.
} 


\section{Results}

Results from the baseline specification, including the two types of defense news shocks and the other endogenous variables, are reported in Figure 1. We plot the point estimates for the impulse responses together with one standard deviation confidence bands, following standard practice in the VAR literature on fiscal policy (see e.g. Blanchard and Perotti, 2002). Figure 1a reports the responses to a shock with expected reversal and Figure $1 \mathrm{~b}$ the responses to a shock without expected reversal. We normalize the two shocks to $1 \%$ of GDP on impact. To better compare the effects of the two shocks, Figure 1c plots the impulse responses of the endogenous variables to the two different types of impulses.

From these figures it clearly emerges that there are significant differences in the reaction of the economy to the two types of government spending shocks. Shocks with reversal (figure 1a) have expansionary effects on output, consumption and investments. Fiscal multipliers - expressed as the percentage response of variables to the $1 \%$ of GDP government spending shocks - peak at around 0.8 for output and consumption. Public debt tends to increase for around one year, but declines thereafter by about $3 \%$ compared to the no-shock scenario, after four years. The reduction in public debt is explained by the automatic reaction of the government budget balance to the output boost which generates higher tax revenues and lower social expenditures. As regards the other variables, expected inflation falls on impact by around 0.25 percentage points but becomes insignificantly different from zero from the fourth quarter following the shock. This behaviour can be explained as the combined result of two opposing effects. On the one hand, the boost in demand following the shock is likely to exert upward pressures on future price expectations. On the other hand, the perception of a future spending reversal should bring expected inflation down immediately. In addition, the reduction in the stock of public debt should translate into lower inflation expectations, given that the perceived risk of future public debt monetization is lower. Overall, while in the short-run the deflationary effects stemming from the latter two channels seem to prevail it turns out that, over the longer run, the effects offset each other. ${ }^{17}$ Finally, the response of monetary policy to the fiscal shock, while in general not statistically different from zero, seems to be broadly consistent with a central bank following a Taylor-type rule: the central bank is

\footnotetext{
${ }^{17}$ Note that also other VAR studies find a negative short-run inflation response to spending shocks for the US (see e.g. Perotti, 2005).
} 
expected to raise the policy interest rate as a response to the increase in output over the medium-run. At the same time, the fall in expected inflation makes the reaction milder in the short-run. This is reflected in the fact that the baseline response of the federal fund rate follows an "S" shape: on impact it decreases somewhat, then it starts increasing as expected inflation and output increase.

The results indicate that - in contrast to the previous case - fiscal shocks without reversal have a contractionary effect on the economy (Figure 1b). Output, consumption and investment decrease for the first year after the shock, then revert back to zero and increase somewhat at the end of the horizon. The short-run contraction is however not very large for GDP and consumption (around $0.2 \%$ ) while it is more sizeable for private investment (around 1\%). As a consequence of the fiscal stimulus and the contraction in economic activity, the stock of public debt increases over the whole horizon (by up to $0.6 \%$ one and a half year after the shock). Expected inflation falls slightly on impact (-0.04 p.p.) and remains negative (though small) over the entire horizon. In this case, deflationary expectations stemming from the contraction in real activity seem to prevail over other forces. The response of the federal fund rate again seems consistent with the Fed following a Taylor rule: the central bank cuts the policy interest rate to counteract lower real activity and lower expected inflation. ${ }^{18}$

To formally test the statistical significance of the difference between the two scenarios (jointly plotted in Figure 1c) we construct a test based on the distribution of the bootstrapped impulse responses. We focus on the main variables of interest: public debt, GDP, private consumption and investment. At every replication of the bootstrap we compute the difference between the impulse responses for the two types of shocks, i.e. with and without reversal, for every horizon $t$ and then compute the $68 \%$ confidence interval for each horizon. The results from this test are plotted in Figure 1d. The areas within the dashed black lines represent the $68 \%$ confidence interval with the thick line representing its median. Hence, if the confidence interval does not contain the zero we can conclude that the differences between impulse responses are also significant at the indicated statistical level. The results broadly confirm the impression from the previous

\footnotetext{
${ }^{18}$ Figure $1 \mathrm{~b}$ shows that the shock with reversal reacts negatively and significantly at the $4^{\text {th }}$-quarter horizon to the shock without reversal. However, the defense news shocks are by definition exogenous and unexpected, therefore they should not react to each other. Therefore, the few cases in which the response of one shock to the other is statistically significant are necessarily driven by estimation error. At the same time, the significant 4 th-quarter response of figure $1 \mathrm{~b}$ is very small in size (i.e. around -0.1) therefore should not have a major impact on the results, which mainly are driven by the impulse on the "non reversal" shock. The latter is indeed sizeable and equal to $1 \%$ of GDP on impact.
} 
figures: the responses of public debt are statistically different both on impact and in the longer-run (after about 8 quarters) while the responses of output and consumption are statistically different throughout the entire horizon. Investments instead result statistically different between 3 and 8 quarters after the shock.

These results may be discussed in the context of the debate on Keynesian vs. Non Keynesian effects of fiscal policy. In fact, it may be argued that the positive and sizeable effects of fiscal expansions reflect the standard (positive) Keynesian effect in the short-run and an amplifying effect resulting from the fact that the shock is perceived as being reabsorbed - at least partially - by lower future spending. The expectation of lower future taxes and the resulting positive "wealth effect" reinforces therefore the expansionary shortrun effects of the fiscal stimulus. On the other hand, if a fiscal expansion is followed by continued above-trend spending growth, the standard Keynesian effect is counteracted by the perception of a future fiscal tightening, leading to a contraction in aggregate demand. In sum, this would imply that multipliers from the first type of shocks ("with reversal") are expected to be larger than those in the second case ("without reversal"). Our results show that this is indeed the case. In particular, for the shocks without reversal, the negative effect coming from the expectations of a future fiscal tightening tends to dominate the positive Keynesian effect, leading to a (moderately) negative effect on output and consumption in the short-run.

The same line of argument - but reversed in sign - can be carried out for the effects of negative fiscal shocks. In the case of negative fiscal shocks followed by expected reversal, the standard (Keynesian) contraction in aggregate demand would be further aggravated by the expectations of future increase in spending and consequently higher expected future taxes thus producing a large negative multiplier due to the combined effect of these two channels. At the same time, when a fiscal consolidation is followed by expectations of further reduction in spending the standard (negative) Keynesian effect is counteracted by the expectations of more sound future fiscal positions which tend to increase aggregate demand today. This is the channel that has been investigated by the literature on "expansionary fiscal contractions", or the so called Non-Keynesian effects of fiscal policy. All in all, this framework helps to interpret our results in that positive and negative shocks with expected reversal are associated with a reaction of output which tends to be of the same sign of the shock, due to the combined effect of the "Keynesian channel" and the "expectation channel", which work in the same direction. At the same time, our evidence indicates that positive and negative shocks without expected reversal generate a reaction of 
output which has an opposite sign compared to the shock, due to fact that the "expectation channel" tends to prevail on the "Keynesian channel" in the short-run.

\section{Robustness checks}

In this section we present a battery of robustness checks. First, it is checked whether the results from the baseline estimation carry through when adding extra endogenous variables. This will also serve to investigate other important determinants of the differences in the response to the two types of shocks. Alternative identification approaches are tested in the second sub-section: robustness is checked with regard to (i) the choice of the horizon for the evaluation of past spending growth when identifying the two types of shocks, (ii) the ordering of the shocks and (iii) the timing of the shocks relative to the formation of the SPF forecasts. All in all, these tests confirm that the central findings of the paper - i.e. the ones related to the different reaction of debt, output and consumption under the two scenarios - are broadly robust.

\subsection{Additional variables}

The results from the first set of robustness checks are reported in Figures 2 through 5 . We add one variable at a time to avoid problems of over-parametrization and of degrees of freedom in estimation. In these Figures, for expositional reasons, we omit to report the responses of the defense news shocks to the shocks themselves. In the following, we will only comment on the responses to positive shocks, with and without reversal (responses to negative shocks can be interpreted symmetrically).

We first include a consumer confidence index as an additional endogenous variable in the VAR. In fact, the occurrence of the shock and the associated expectations about the future path of government spending can influence today's perception about the future macroeconomic environment. This, in turn, may have an effect on the real economy at the time of the shock. In case of positive shocks with reversal, for instance, the combined effect of the fiscal stimulus and of a less likely future fiscal tightening can work towards increasing agents' confidence, boosting private consumption and investment today. On the other hand, when a positive shock is followed by non reversal, the positive effect coming from the "Keynesian" channel can be offset by concerns about the future fiscal stance. This would in turn negatively affect private consumption and investments (see, for 
example, Caballero and Pyndick 1996). This possible channel of transmission is tested using the quarterly consumers' confidence indicator constructed by the University of Michigan. Figure 2a shows that the confidence index reacts with a steep increase to fiscal shocks with reversal, suggesting that fiscal restraint is considered to be beneficial for overall economic conditions. The response to fiscal shocks without reversals is negative in the short-run, turning slightly positive only after 8 quarters. In terms of magnitude, the response of the confidence index is about five times larger in the case of shocks with reversal than in the other case, for horizons up to two years. Interestingly, the behaviour of private investment and consumption seems to mirror the response of the confidence index, indicating that this channel of transmission indeed is relevant for explaining the differences between the two shocks.

Next, we investigate the effects of our two types of fiscal shocks on the slope of the yield curve. We saw that shocks with expected reversal induce an increase in the confidence index and, in turn, an output expansion. Therefore, agents should demand a lower interest rate on long-term bonds under this scenario. In addition, shocks with expected reversal are associated with a short-run increase in public debt, and with a sizeable decline of debt in the medium to long-run. Consequently, the time path of debt might affect the term premium requested by markets participants on government bonds. We proxy the term premium with the slope of the yield curve, computed as the difference between the yield on 10 years bonds and the 3 months treasury bill. The reaction of the term premium is important because it can serve as a benchmark for the price of lending to the private sector which affects private consumption and investment decisions. The results from the VAR including this variable are reported in Figures $3 \mathrm{a}$ and $3 \mathrm{~b}$ : first, we see that the response of the other variables included in the baseline model does not change significantly if the slope of the yield curve is added. Second, Figure 3a highlights that - in the case of shocks with reversal - the response of the slope of the yield curve indeed broadly mirrors the response of public debt: it is positive in the short-run but then starts falling as soon as public debt decreases. It becomes negative and significant 4 quarters after the shock and then starts converging back to zero. When we consider fiscal shocks without reversal, instead, the slope of the yield curve responds positively and increases up to $0.1 \%$ which is reached in the fifth quarter after the shock. After the peak it remains in the positive territory and reverts back slowly to around zero in the medium run.

Next, we focus on real wages. Following Mountford and Uhlig (2009), we use the real compensation per hour of the non farm business sector, expressed it in the logarithmic 
scale to be consistent with the other variables in the VAR. Figure $4 \mathrm{a}$ and $4 \mathrm{~b}$ show that including real wages does not alter the response of the variables included in the baseline model both in terms of shape and in terms of magnitude. Moreover, results show that after a shock with reversal real wages increase significantly and only start declining again after around six quarters. The increase in real wages can be explained, on the one hand, by increased labour demand following the expansive fiscal shock and, on the other hand, by a rise in labour productivity which is likely to follow the upsurge of investments that takes place under this scenario. As a response to the shocks without reversals, real wages decrease somewhat in the short-run and then increase, becoming statistically insignificant after one year. Again, this broadly reflects the dynamic behaviour of investment which decreases in the short-run and picks up after about one year following the non-reversed shock. Figure $4 \mathrm{~b}$ focuses on the difference in the responses under the two scenarios. In particular, it shows that for most of the variables of interest the one standard deviation confidence interval tends not to contain the zero, therefore rejecting the null hypothesis of equal responses.

Finally, we incorporate the unemployment rate in the baseline VAR. We use the quarterly average of the monthly civilian unemployment rate taken from the St. Louis Fed's FRED database. Intuitively, we would expect the unemployment rate to follow the path of output and investments, i.e. decreasing in the case of shocks with reversal and increasing in the other case. An increase in investments is expected to raise labour productivity which in turn would translate into an incentive for employers to increase their labour demand. However, if hours worked also reacted to the fiscal expansion this would impair the capacity of fiscal policy to affect unemployment. Figure $5 \mathrm{a}$ and $5 \mathrm{~b}$ show that unemployment indeed reacts to the two types of fiscal shocks. In particular, unemployment decreases in the cases of shocks with expected reversal and increases in the other case. It is worth noticing, however, that in the latter case unemployment initially increases before starting to decrease 8 quarters after the shock and turning negative after 10 quarters. This mirrors the path of output. In terms of magnitude, the responses are not large: for shocks with reversal the response of unemployment is "V" shaped with a minimum at around $0.25 \%$ while in cases of shocks without reversal unemployment peaks at about $+0.1 \%$ one year after the shock. Finally, Figure $5 \mathrm{~b}$ shows that the responses of unemployment tend to be statistically different in the two cases. 


\subsection{Alternative identification approach}

As explained in Section 3, the strategy to distinguish the Ramey shocks requires to select a horizon for which historical averages for spending growth are computed. For the baseline specification, we used 15 year averages. Here, we employ a longer horizon, i.e. we repeat the identification of shocks by comparing the growth rates of expectations to the average growth rate of spending computed over a "historical" interval of 25 years of past data. ${ }^{19}$ Using this longer horizon changes the classification of some shocks (between "with reversal" and "without reversal"). Table 5 shows the new distribution of the defense news shocks across the two categories under this alternative identification scheme. Figures $6 \mathrm{a}$ and $6 \mathrm{~b}$ show that the choice of the horizon does not alter significantly the baseline results, both in terms of shape and magnitude of the impulse responses. More specifically, fiscal shocks with expected reversal have a positive effect on real variables and trigger a reduction in the stock of public debt while shocks without expected reversal tend to have opposite effects.

Next, we check whether our identification strategy is robust to the ordering of variables. Given that we only identify innovations associated with the first two variables in the VAR, the relative ordering of the other variables will not affect the results. Hence, it is sufficient to check whether our results change if we invert the two defense news shock that we have in first and second position. Thus far the analysis was conducted by ordering shocks with reversal first and shocks without reversal as second. Figures $7 \mathrm{a}$ and $7 \mathrm{~b}$ show that if we invert this ordering, the results from the baseline estimation are unaffected, hence proving our results robust to the use of recursive identification. ${ }^{20}$

Finally, we control the robustness of the results with respect to those shocks which take place after the release of the SPF. In particular, we repeat the baseline exercise but we drop the 4 shocks that occur after the publication of the SPF (as reported in Appendix B). Results from this robustness check are reported in figures $8 \mathrm{a}$ and $8 \mathrm{~b}$ : it emerges that the dynamics of the variables is broadly preserved, both qualitatively and quantitatively. If

\footnotetext{
${ }^{19}$ The choice of the horizons to use as robustness checks was made keeping into consideration that, on one hand, we want a time span long enough so that we can consider the average growth rate of past spending as "trend growth". On the other hand, we cannot choose an horizon longer than 25 - 30 years because otherwise the computation of the average growth rate of public spending would have been influenced by the large swings that public spending had during the fifties as a consequence of the Korean war.

${ }^{20}$ The results of the test (figure $7 \mathrm{~b}$ ) are exactly the mirror image of those for the baseline case (figure $1 \mathrm{~b}$ ). This is due to the fact that after the inversion of the defense news variables the test is now constructed as the difference between the impulse responses for shocks without reversal and that for shocks with reversal".
} 
anything, the negative responses of output, consumption and investment for the "non reversal case" is even somewhat stronger than in the baseline exercise.

\section{Conclusions}

This paper proposes a new empirical approach to analyze the fiscal transmission mechanism. We take inspiration from Corsetti et al. $(2009,2010)$ and show that expectations about the future fiscal policy stance play a key role in shaping the macroeconomic responses to fiscal shocks. We show that there are important differences in the transmission of fiscal policy shocks depending on the types of shock identified. In particular, fiscal shocks not accompanied by an expected spending reversal cause an increase in the public debt burden and a decrease in confidence which depresses real activity. In contrast, fiscal shocks accompanied by an expected spending reversal effectively boost economic activity and tend to reduce the stock of public debt in the longrun. These results suggest that the effectiveness of discretionary fiscal policy measures depend on what agents expect about the future path of public spending. This provides interesting insights for the ongoing debate on Keynesian vs. Non Keynesian effects of discretionary fiscal policy measures. Our analysis suggests that the standard Keynesian effects of changes in government spending are accompanied by important expectational effects which depend on how economic agents perceive the future path of public finances at the time a spending shock occurs. In particular, wealth effects related the expectation of subdued spending growth and, as a result, lower future taxes may counteract standard Keynesian multiplier effects. As a consequence, a fiscal contraction may turn out to be expansionary if the expectation channel becomes sufficiently strong. Such considerations seem to be of particular relevance in the context of the ongoing debate regarding the fiscal exit from the major budgetary loosening in the context of 2009/10 financial and economic crisis. 


\section{References}

Afonso, A. (2010), "Expansionary fiscal consolidations in Europe: new evidence", Applied Economics Letters, Taylor and Francis Journals, vol. 17(2), pages 105-109.

Alesina, A. and S. Ardagna (1998). "Tales of Fiscal Contractions," Economic Policy, 27, 487-545.

Alesina A. and R. Perotti (1997), "Fiscal Adjustments in OECD Countries: Composition and Macroeconomic Effects”, IMF Working Paper 96/70.

Ardagna S. (2004), "Fiscal Stabilizations: When do they Work and Why", European Economic Review, 48, pp. 1047 - 1074.

Auerbach A. J. and Y. Gorodnichenko (2010), "Measuring the Output Responses of Fiscal Policy”, NBER Working Paper No. 16311, August.

Baxter, M., and R. G. King (1993), "Fiscal Policy in General Equilibrium," American Economic Review, 83, 315-334.

Beetsma, R. and M. Giuliodori (2011), "The Effects of Government Purchases Shocks: Review and Estimates for the EU", The Economic Journal, 121(55), pp. 4-32.

Bénétrix, A. and P. R. Lane (2009), "The Impact of Fiscal Shocks on the Irish Economy”, The Economic and Social Review, Economic and Social Studies, vol. 40(4), pp. 407-434.

Berben R. P. and T. Brosens (2007), "The Impact of Government Debt on Private Consumption in OECD Countries", Economic Letters 94, pp. 220 - 225.

Bilbiie F. O., Meier A. and G. J. Muller (2008), "What Accounts for the Changes in U.S. Fiscal Policy Transmission?", Journal of Money Credit and Banking, Blackwell Publishing, vol. 40(7) October, pp. 1439-1470. 
Blanchard O. and Perotti R. (2002), "An Empirical Characterization of the Dynamic Effects of Changes in Government Spending and Taxes on Output", Quarterly Journal of Economics, Vol. 117, N. 4 (Nov. 2002), pp. 1329 - 1368.

Caballero R., Pyndick R. S. (1996), “Uncertainty, Investment and Industry Evolution”, International Economic Review, Vol. 37, August, pp. 641 - 662.

Canova, F. and E. Pappa (2011), "Fiscal Policy, Pricing Frictions and Monetary Accomodation", mimeo.

Christiano L. J., Eichembaum M. and C. L. Evans (1999), "Monetary Policy Shocks: What Have We Learned, and To What End", in Taylor and Woodford, Handbook of Monetary Economics, 1999.

Corsetti G., Meier A. and G. J. Muller (2009), "Fiscal Stimulus with Spending Reversals", April 2009, IMF Working Paper N. 09106.

Corsetti G., Kuester K., Meier A. and G. J. Muller (2010), "Debt Consolidation and Fiscal Stabilization of Deep Recessions", American Economic Review, Vol. 100(2), May 2010, pp. $41-45$.

Davig T. and E. M. Leeper (2011), "Monetary-Fiscal Policy Interactions and Fiscal Stimulus”, European Economic Review, Vol. 55(2), February 2011, pp. 211-227 .

Edelberg W., Eichenbaum M. and J. D. M. Fisher (1999), "Understanding the Effects of a Shock to Government Purchases“, Review of Economic Dynamics, Vol. 2, January, pp. $166-206$.

Favero C. and F. Giavazzi (2007), "Debt and the Effects of Fiscal Policy", NBER Working Paper No 12833.

Fatas A. and I. Mihov (2001), "The Effects of Fiscal Policy on Consumption and Employment: Theory and Evidence”, CEPR Discussion Paper N. 2760. 
Forni M. and L. Gambetti (2010), "Fiscal Foresight and the Effects of Government Spending”, CEPR discussion paper N. 7840, May 2010.

Furceri D. and A. Zdzienicka (2011) "The Effects of Social Spending on Economic Activity: Empirical Evidence from a Panel of OECD Countries”, MPRA Paper No. 30356, University Library of Munich, Germany.

Gali J., Lopez Salido J. D. and J. Vallès (2007), "Understanding the Effects of Government Spending on Consumption", Journal of the European Economic Association, March 2007, 5(1), pp. $227-270$.

Giavazzi F., Jappelli T. and M. Pagano (2000), "Searching for Non Linear Effects of Fiscal Policy: Evidence From Industrial and Developing Countries", European Economic Review, Vol. 44(7), June 2000, pp. 1259 - 1289.

Giavazzi F. and M. Pagano (1990) "Can Severe Fiscal Contractions be Expansionary? Tales of two small European Countries", in NBER Macroeconomic Annuals, ed. by Olivier Blancharnd and Stanley Fischer, Cambridge Massachusetts, MIT Press.

Giavazzi F. and M. Pagano (1996), "Non-Keynesian Effects of Fiscal Policy Changes: International Evidence and the Swedish Experience", Swedish Economic Policy Review, Vol. 3, pp. $67-103$.

Hemming R., Mahfouz S. and A. Schimmelpfenning (2002), "Fiscal Policy and Economic Activity During Recessions in Advanced Economies”, IMF Working Paper 02/87.

Iltzezki E., Mendoza E. C. A. Vegh (2009), “How Big are Fiscal Multipliers?”, CEPR Policy Insight N. 39, October 2009.

Kirchner, M. (2010), "Expectations-Based Identification of Government Spending Shocks", University of Amsterdam, mimeo. 
Kirchner M., Cimadomo J. and S. Hauptmeier (2010), "Transmission of Government Spending Shocks in the Euro Area: Time Variation and Driving Forces", Tinbergen Institute Discussion Papers, TI 2010-021/2.

Leeper E., Walker T. B. and S. C. S. Yang (2009), "Fiscal Foresight and Information Flows”, NBER Working Paper, WP N. 14630 January 2009.

Mountford A. and H. Uhlig (2009), "What are the Effects of Fiscal Policy Shocks?", Journal of Applied Econometrics, 24(6), pp. 960 - 992.

Perotti R. (2005), "Estimating the Effects of Fiscal Policy in OECD countries", CEPR Discussion Paper N. 4842.

Perotti R. (1999) “Fiscal Policy in Good Times and Bad”, Quarterly Journal of Economics, 114(4), pp. 1399-1346.

Ramey, V. (2009), "Defense News Shocks, 1939-2008: An Analysis Based on News Sources," UCSD manuscript.

Ramey V. (2011), "Identifying Government Spending Shocks: It's all in the Timing", Quarterly Journal of Economics, 126(1), pp. 1-50.

Ramey V. and M. D. Shapiro (1998), "Costly Capital Reallocation and the Effects of Government Spending”, Carnegie-Rochester Conference Series on Public Policy. Vol. 48, June 1998, pp. $145-194$.

Romer D. H. and C. D. Romer (2010), "The Macroeconomic Effects of Tax Changes: Estimates Based on a new Measure of Fiscal Shocks", American Economic Review 100, June 2010, pp. $763-801$.

Spilimbergo A., Symansky S. and M. Schilnder (2009), "Fiscal Multipliers", IMF Staff Position Note No 11, May. 
Tagkalakis A. (2008), “The Effects of Fiscal Policy on Consumption in Recessions and Expansions", Journal of Public Economics, 93 (2008), pp. 1486 - 1508.

Wyplosz C. (2005), "Fiscal Policy: Institutions Versus Rules", National Institute Economic Review, N. 191, January 2005, pp. $70-84$.

\section{Tables}

Table 1. Ramey's defense news shocks - with and without expected reversal

\begin{tabular}{|c|c|c|c|}
\hline Quarter & $\begin{array}{l}\text { PDV of expected } \\
\text { changes in } \\
\text { spending (Bil. of } \\
\text { current USD) } \\
\end{array}$ & $\begin{array}{c}\text { PDV of expected } \\
\text { changes in spending } \\
\text { (\% of prev. quarter } \\
\text { GDP) }\end{array}$ & $\begin{array}{l}\text { Type of shock } \\
\text { (Baseline } \\
\text { Identification) }\end{array}$ \\
\hline & $(1)$ & (2) & (3) \\
\hline $1986 q 4$ & -89.4 & -1.99 & With Reversal \\
\hline $1988 \mathrm{q} 1$ & -242 & -4.96 & No Reversal \\
\hline $1988 \mathrm{q} 4$ & -58.8 & -1.14 & No Reversal \\
\hline $1989 q 4$ & -507.6 & -9.17 & No Reversal \\
\hline $1990 q 4$ & 112.1 & 1.92 & With Reversal \\
\hline $1991 q 4$ & -112.1 & -1.86 & No Reversal \\
\hline $1999 q 1$ & 15 & 0.17 & With Reversal \\
\hline $2001 \mathrm{q} 3$ & 97.1 & 0.94 & No Reversal \\
\hline $2002 q 1$ & 296.3 & 2.86 & No Reversal \\
\hline $2002 q 3$ & 93 & 0.88 & No Reversal \\
\hline $2003 q 1$ & 123.8 & 1.15 & With Reversal \\
\hline $2003 q 3$ & 41 & 0.37 & With Reversal \\
\hline $2003 q 4$ & 78.2 & 0.69 & No Reversal \\
\hline $2004 q 2$ & 25 & 0.22 & With Reversal \\
\hline $2005 q 1$ & 100 & 0.82 & No Reversal \\
\hline $2006 \mathrm{q} 2$ & 227.7 & 1.73 & No Reversal \\
\hline $2007 q 4$ & 739.3 & 5.21 & No Reversal \\
\hline
\end{tabular}

Table 2. Number of positive and negative shocks, with and without reversal

\begin{tabular}{llll}
\hline \hline & $\begin{array}{l}\text { With } \\
\text { Reversal }\end{array}$ & $\begin{array}{l}\text { Without } \\
\text { Reversal }\end{array}$ & TOTAL \\
\hline Positive Shocks & 5 & 4 & $\mathbf{9}$ \\
Negative Shocks & 1 & 7 & $\mathbf{8}$ \\
TOTAL & $\mathbf{6}$ & $\mathbf{1 1}$ & $\mathbf{1 7}$ \\
\hline \hline
\end{tabular}


Table 3. Summary statistics: positive and negative shocks

\begin{tabular}{lcc|cc}
\hline \hline & \multicolumn{2}{c|}{ Bil. USD } & \% of Prev. quarter GDP \\
\hline & Mean & Std Dev & Mean & Std Dev \\
Positive Shocks & 162.37 & 198.73 & 1.41 & 1.43 \\
Negative Shocks & -201.98 & 184.56 & -3.82 & 3.32 \\
\hline \hline
\end{tabular}

Table 4. Summary statistics: shocks with and without expected reversal

\begin{tabular}{lll|ll}
\hline \hline \multicolumn{5}{c}{ With Reversal } \\
\hline & Bil. USD & \multicolumn{2}{c}{ \% Previous quarter GDP } \\
\hline Mean & Std Dev & Mean & Std. Dev. \\
Negitive Shocks & 63.38 & 50.84 & 0.77 & 0.76 \\
\hline \hline \multicolumn{7}{c|}{ Without Reversal } & \multicolumn{1}{c}{ \% Previous quarter GDP } \\
\hline \multicolumn{7}{c}{ Bil. USD } & Mean & Std. Dev. \\
\hline Positive Shocks & -89.4 & Std Dev & 1.87 & 1.66 \\
Negative Shocks & Mean & 238.08 & -4.28 & 3.65 \\
\hline \hline
\end{tabular}

Table 5. Number of positive and negative shocks, with and without expected Reversal (Identification using historical average over 25 years)

\begin{tabular}{llll}
\hline \hline & $\begin{array}{l}\text { With } \\
\text { Reversal }\end{array}$ & $\begin{array}{l}\text { Without } \\
\text { Reversal }\end{array}$ & TOTAL \\
\hline Positive Shocks & 8 & 4 & 12 \\
Negative Shocks & 1 & 4 & $\mathbf{5}$ \\
TOTAL & $\mathbf{9}$ & $\mathbf{8}$ & $\mathbf{1 7}$ \\
\hline \hline
\end{tabular}

\section{Appendix A. Definition of variables}

(i) Ramey Shocks: They are the "Defense News Shocks" constructed by Ramey (2010) and reported in Table 1.

(ii) Debt: Central Government Debt (per capita), ECB, Statistical Data Warehouse.

(iii) GDP: US Bureau of Economic Analysis's NIPA Table 1.1, row 1

(iv) Consumption: NIPA Table 1.1, row 2

(v) Investments: Private non residential investments, NIPA Tables. 
(vi) Expected Inflation: Expected inflation rate for the following year, expressed in annualized terms; Survey of Professional Forecasters, Federal Reserve Bank of Philadelphia.

(vii) Federal Fund Rate: Simple quarterly average of the monthly federal fund rate, Federal Reserve Bank of New York; the rate is expressed in annualized terms.

(viii) Real Wages: "Non Farm Business Sector: Real Compensation per Hour", series COMPRNFB from the Bureau of Labor Statistics; expressed in logs.

(ix) Unemployment Rate: Civilian unemployment rate, FRED Database, Federal Reserve Bank of St. Louis.

(x) Confidence Index: University of Michigan Confidence Index Indicator; expressed in logs.

(xi) Slope of the Yield Curve: Difference between the return on the 10 years US Government Bonds and the 3 months Treasury Bills; Federal Reserve Bank of New York; both rates are expressed in annualized terms.

10. Appendix B. Timing of Ramey's shocks

\begin{tabular}{ccccc} 
Time & $\begin{array}{c}\text { Shock } \\
\text { (\% of previous } \\
\text { quarter GDP) }\end{array}$ & Timing & $\begin{array}{c}\text { Shock happens } \\
\text { before the release } \\
\text { of the SPF }\end{array}$ & $\begin{array}{c}\text { Shock happens } \\
\text { After the release } \\
\text { of the SPF }\end{array}$ \\
\hline \hline $\mathbf{1 9 8 6 q 4}$ & -1.99 & $03 / 11 / 1986$ & $\mathbf{X}$ & - \\
$\mathbf{1 9 8 8 q 1}$ & -4.96 & $29 / 02 / 1988$ & - & $\mathbf{X}$ \\
$\mathbf{1 9 8 8 q 4}$ & -1.14 & $21 / 11 / 1988$ & $\mathbf{X}$ & - \\
$\mathbf{1 9 8 9 q 4}$ & -9.17 & $25 / 12 / 1989$ & - & $\mathbf{X}$ \\
$\mathbf{1 9 9 0 q 4}$ & 1.92 & $12 / 11 / 1990$ & $\mathbf{X}$ & - \\
$\mathbf{1 9 9 1 q 4}$ & -1.86 & $14 / 10 / 1991$ & $\mathbf{X}$ & - \\
$\mathbf{1 9 9 9 q 1}$ & 0.17 & $11 / 01 / 1999$ & $\mathbf{X}$ & - \\
$\mathbf{2 0 0 1 q 3}$ & 0.94 & $22 / 09 / 2001$ & - & $\mathbf{X}$ \\
$\mathbf{2 0 0 2 q 1}$ & 2.86 & $02 / 02 / 2002$ & $\mathbf{X}$ & - \\
$\mathbf{2 0 0 2 q 3}$ & 0.88 & $30 / 09 / 2002$ & - & $\mathbf{X}$ \\
$\mathbf{2 0 0 3 q 1}$ & 1.15 & $03 / 02 / 2003$ & $\mathbf{X}$ & - \\
$\mathbf{2 0 0 3 q 3}$ & 0.37 & $23 / 05 / 2003$ & $\mathbf{X}$ & - \\
$\mathbf{2 0 0 3 q 4}$ & 0.69 & $01 / 11 / 2003$ & $\mathbf{X}$ & - \\
$\mathbf{2 0 0 4 q 2}$ & 0.22 & $06 / 05 / 2004$ & $\mathbf{X}$ & - \\
$\mathbf{2 0 0 5 q 1}$ & 0.82 & $01 / 03 / 2005$ & $\mathbf{X}$ & - \\
$\mathbf{2 0 0 6 q 2}$ & 1.73 & $27 / 04 / 2006$ & $\mathbf{X}$ & - \\
$\mathbf{2 0 0 7 q 4}$ & 5.21 & $24 / 10 / 2007$ & $\mathbf{X}$ & - \\
\hline \hline
\end{tabular}




\section{Figures}

1a)

\section{Shocks with expected reversal}
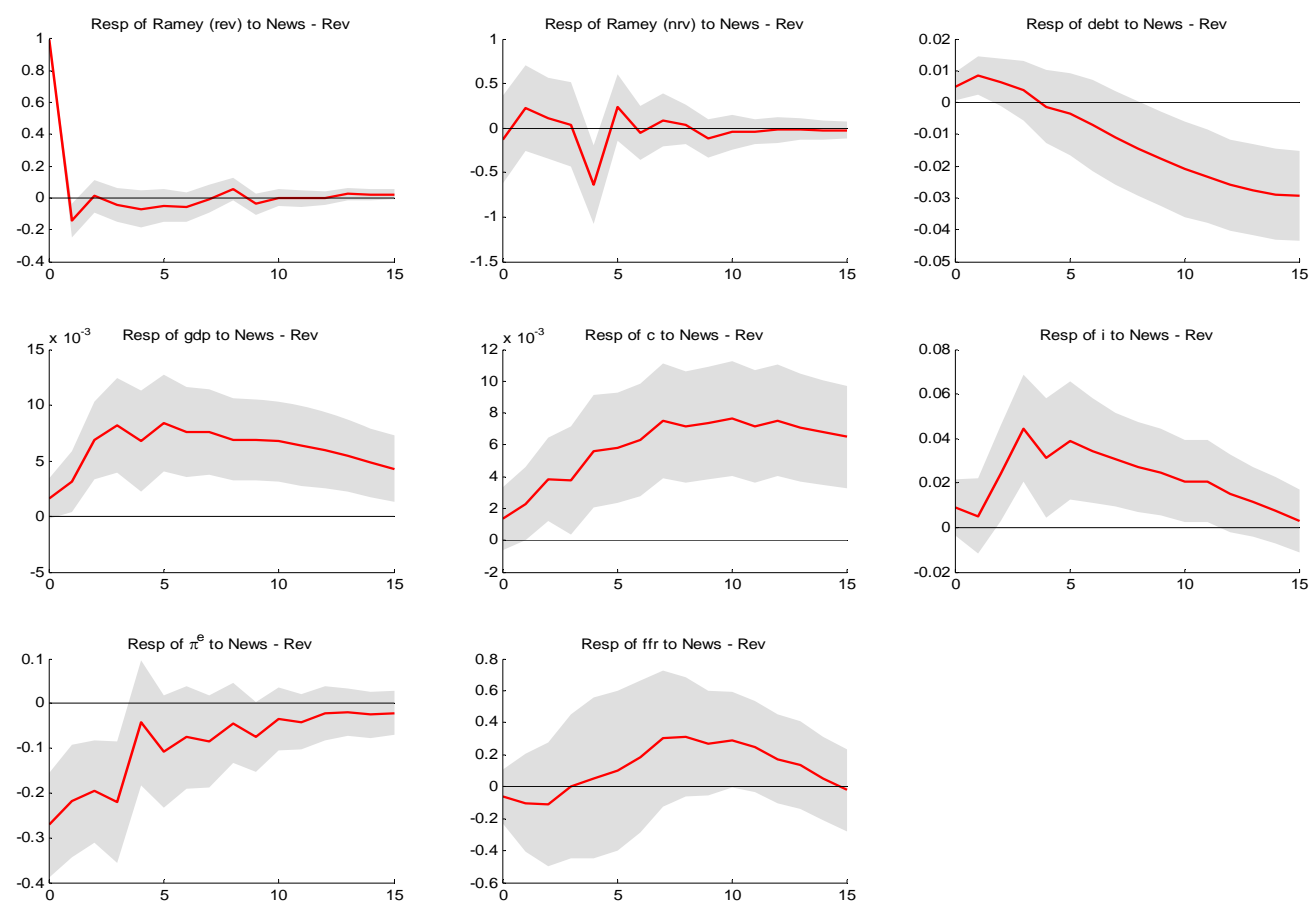

1b) Shocks without expected reversal
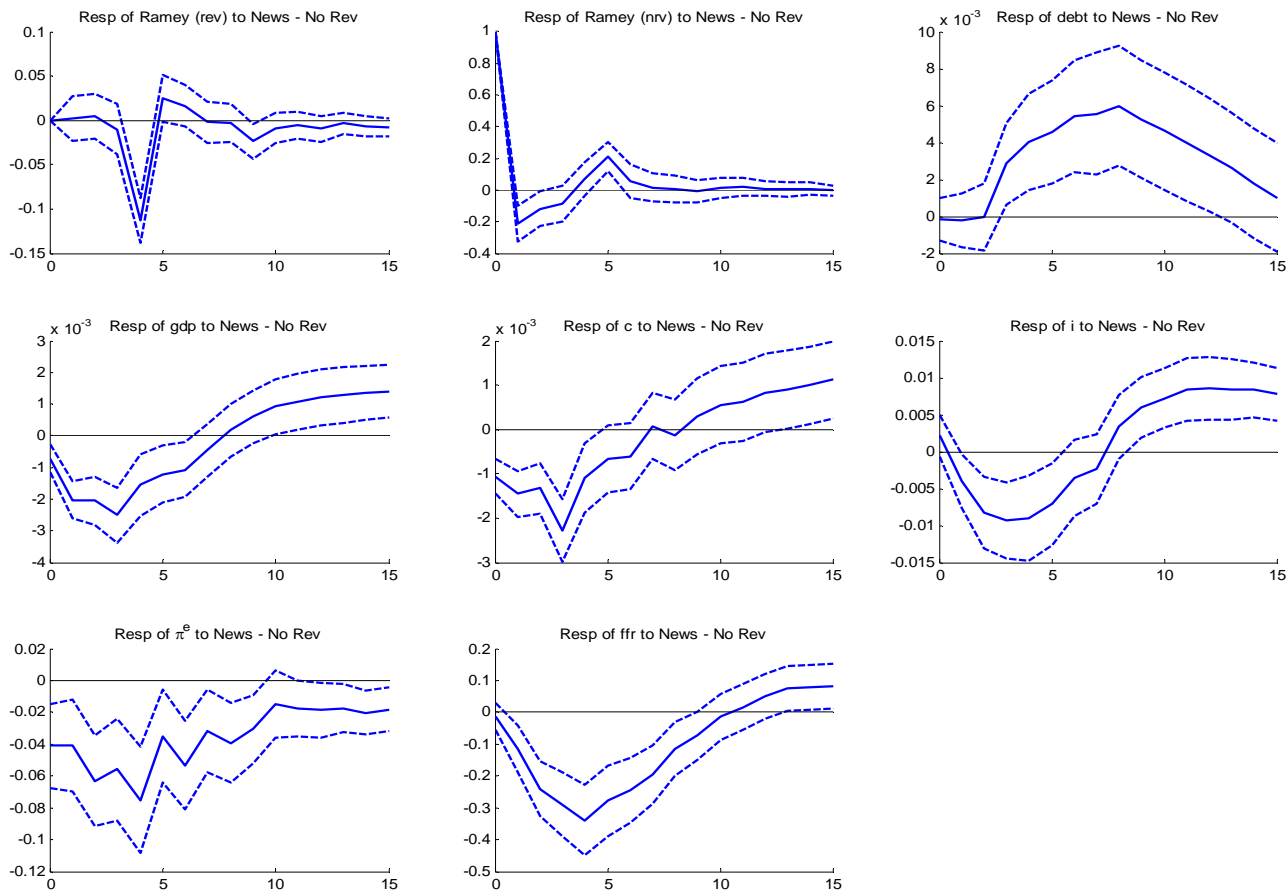

Figure 1a and 1b - BASELINE MODEL: Effects of a defense news shock equal to 1\% of GDP. The effects of a shock with expected reversal in public spending are reported in figure 1a, the effects of a shock without expected reversal in figure 1b. The sample includes US data from 1981Q3 through 2008Q3. 

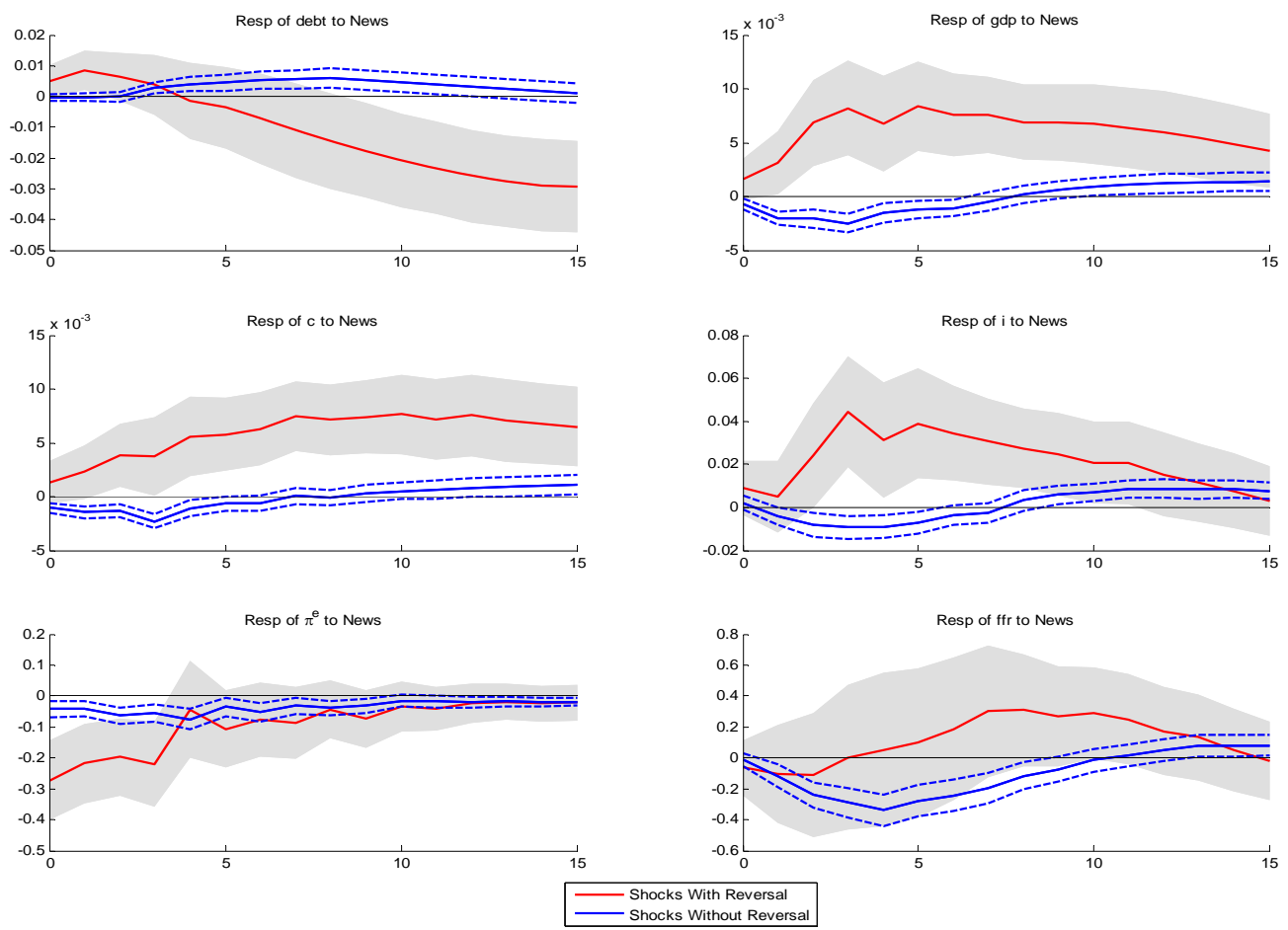

1d) Testing the difference in the effects of the two shocks
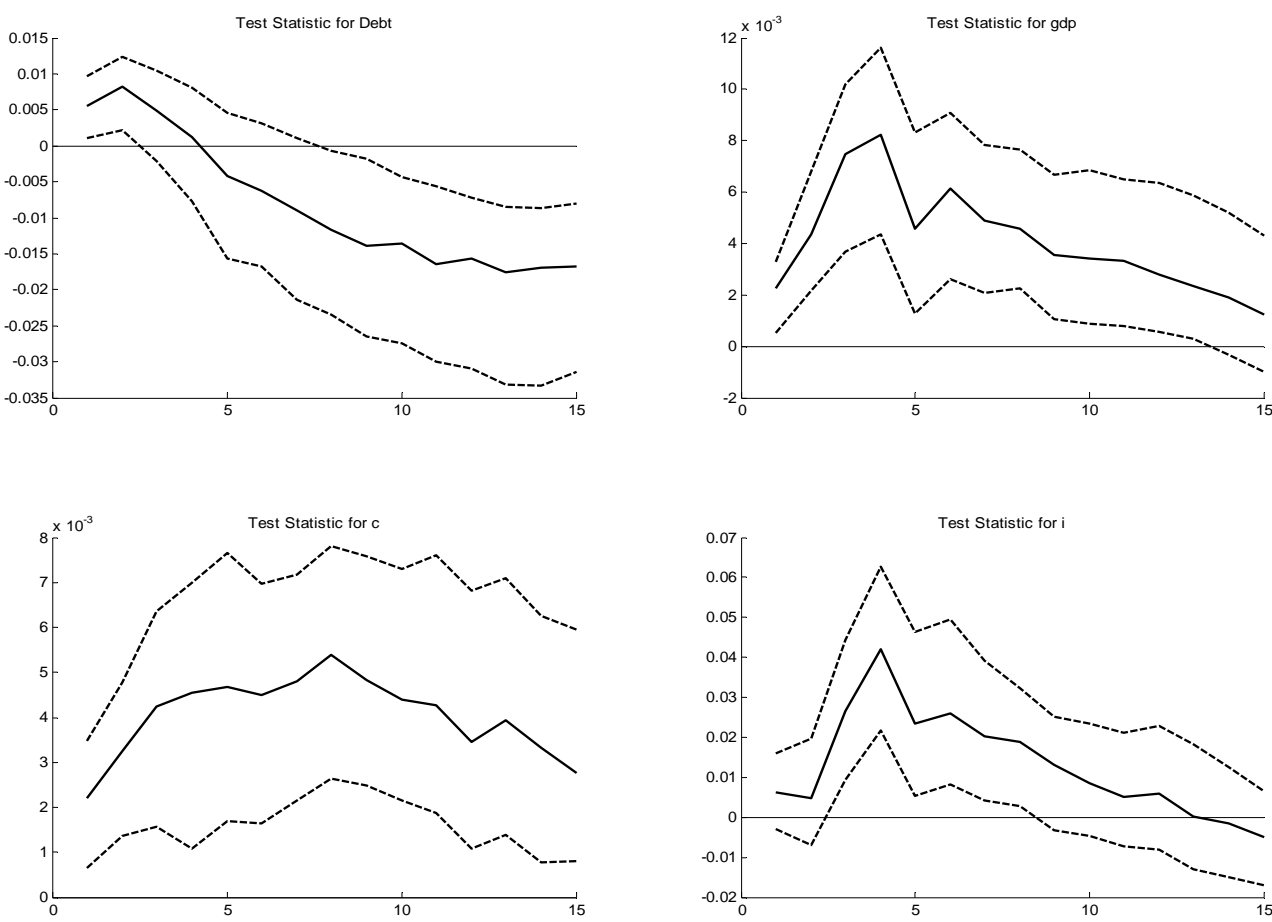

Figure 1c and 1d - BASELINE MODEL: Figure 1c reports a comparison between the effects of shocks with and without expected spending reversals. Figure 1d reports the statistic constructed to test the difference between the impulse responses in the two cases. The two impulse responses are statistical different at the $68 \%$ level for a certain horizon if the confidence bands do not include the zero line at that horizon. 

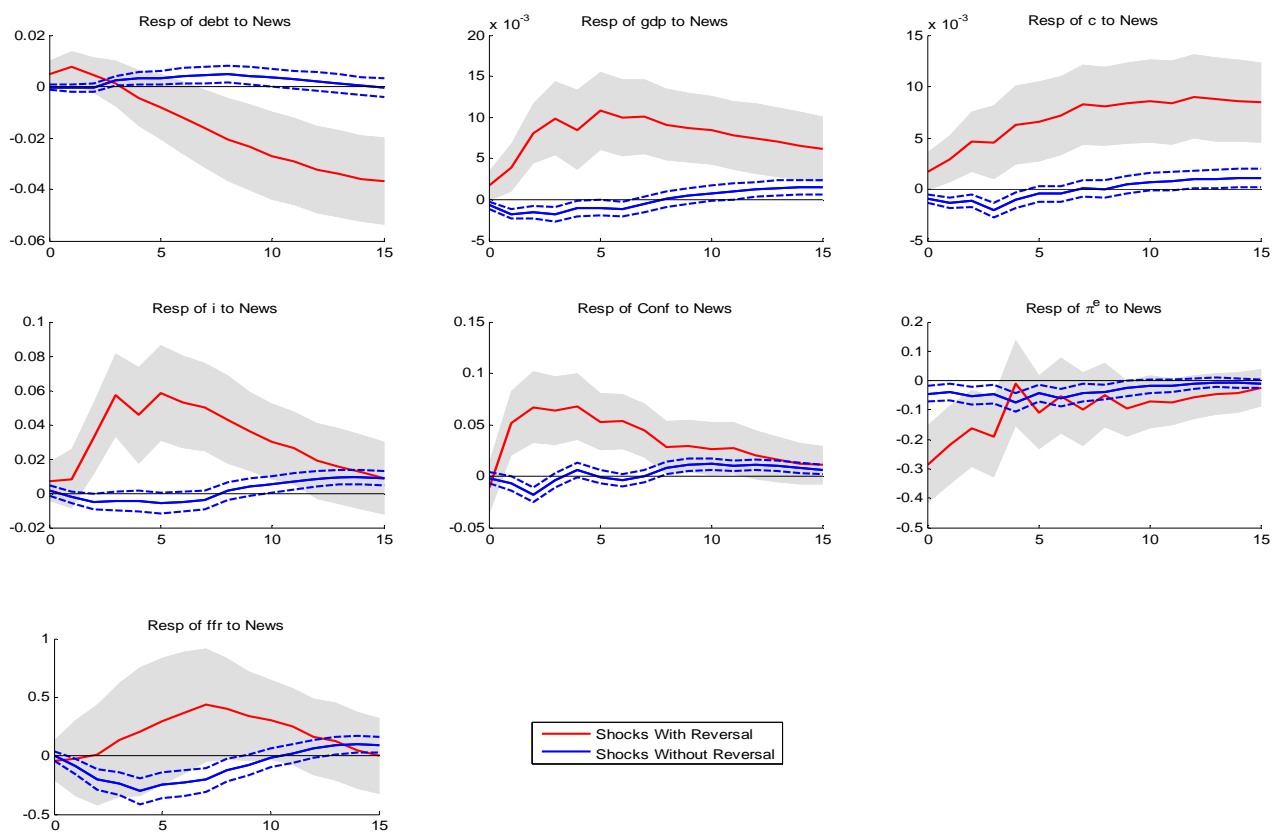

2b)

Testing the difference in the effects of the two shocks
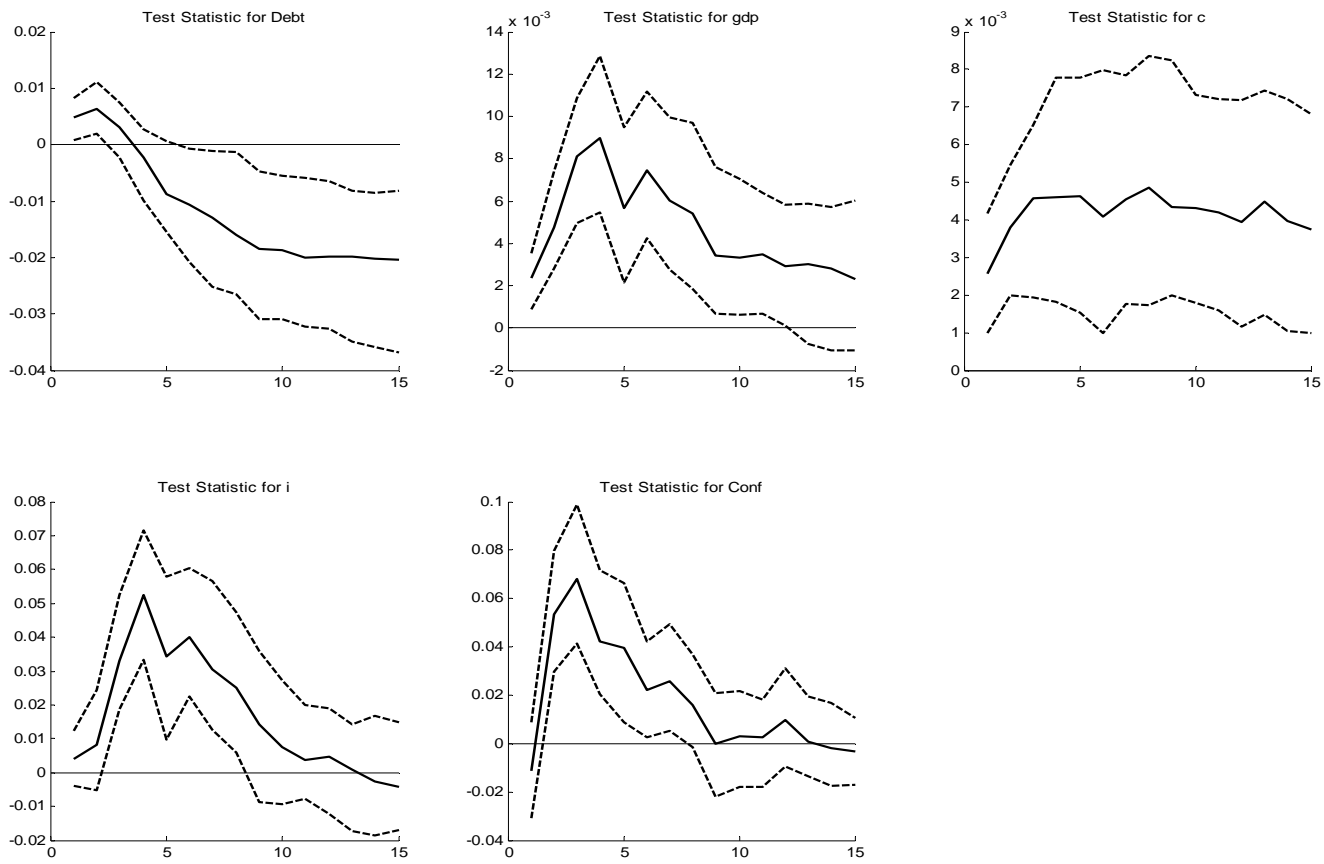

Figure 2a and 2b (Consumers' confidence index): Figure 2a reports a comparison between shocks with and without expected spending reversals, when the VAR model includes also the Consumers confidence index (Conf), published by the University of Michigan. Figure $2 \mathrm{~b}$ reports the statistic constructed to test the difference between the impulse responses in the two cases. The two impulse responses are statistical different at the $68 \%$ level for a certain horizon if the confidence bands do not include the zero line at that horizon. 

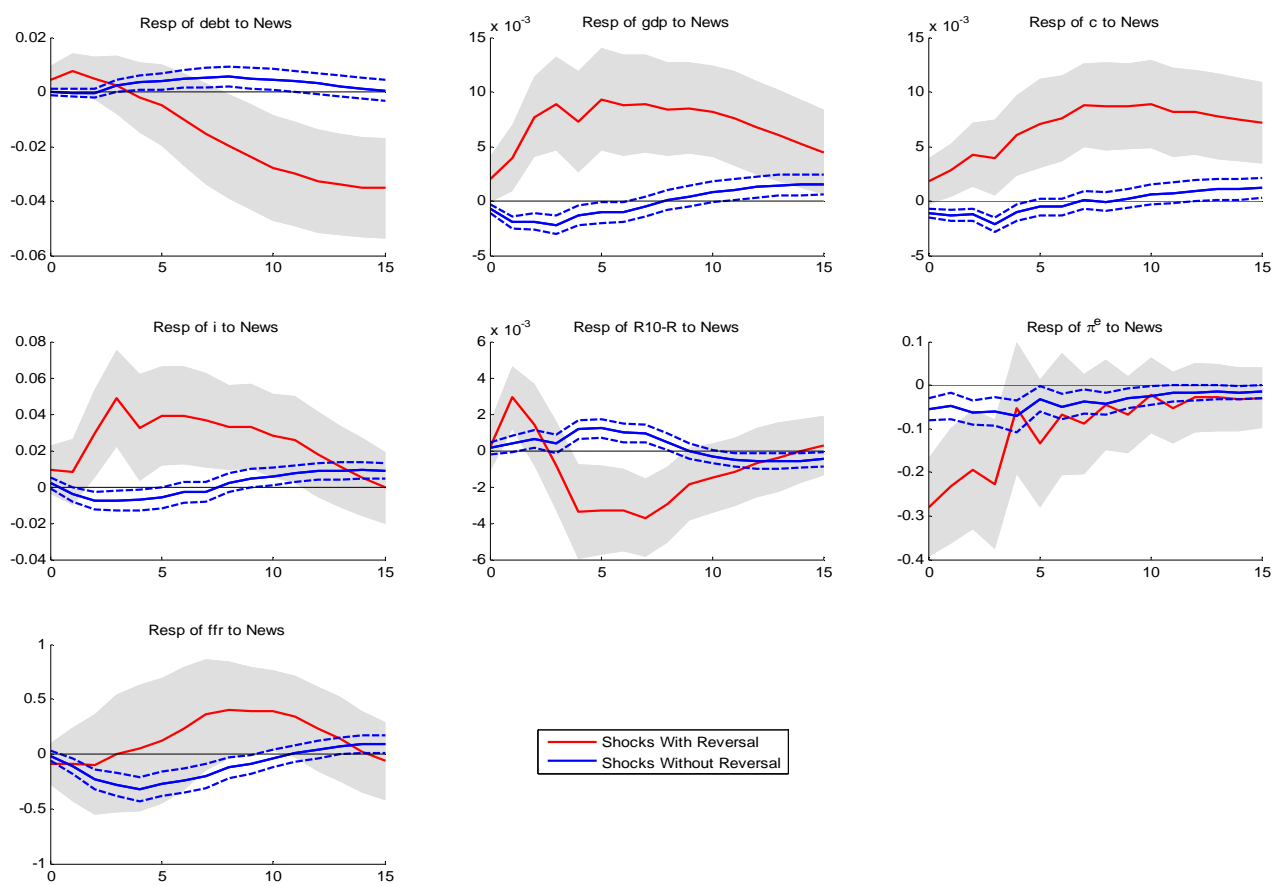

\section{- Shocks With Reversal} Shocks Without Reversa

\section{Testing the difference in the effects of the two shocks}
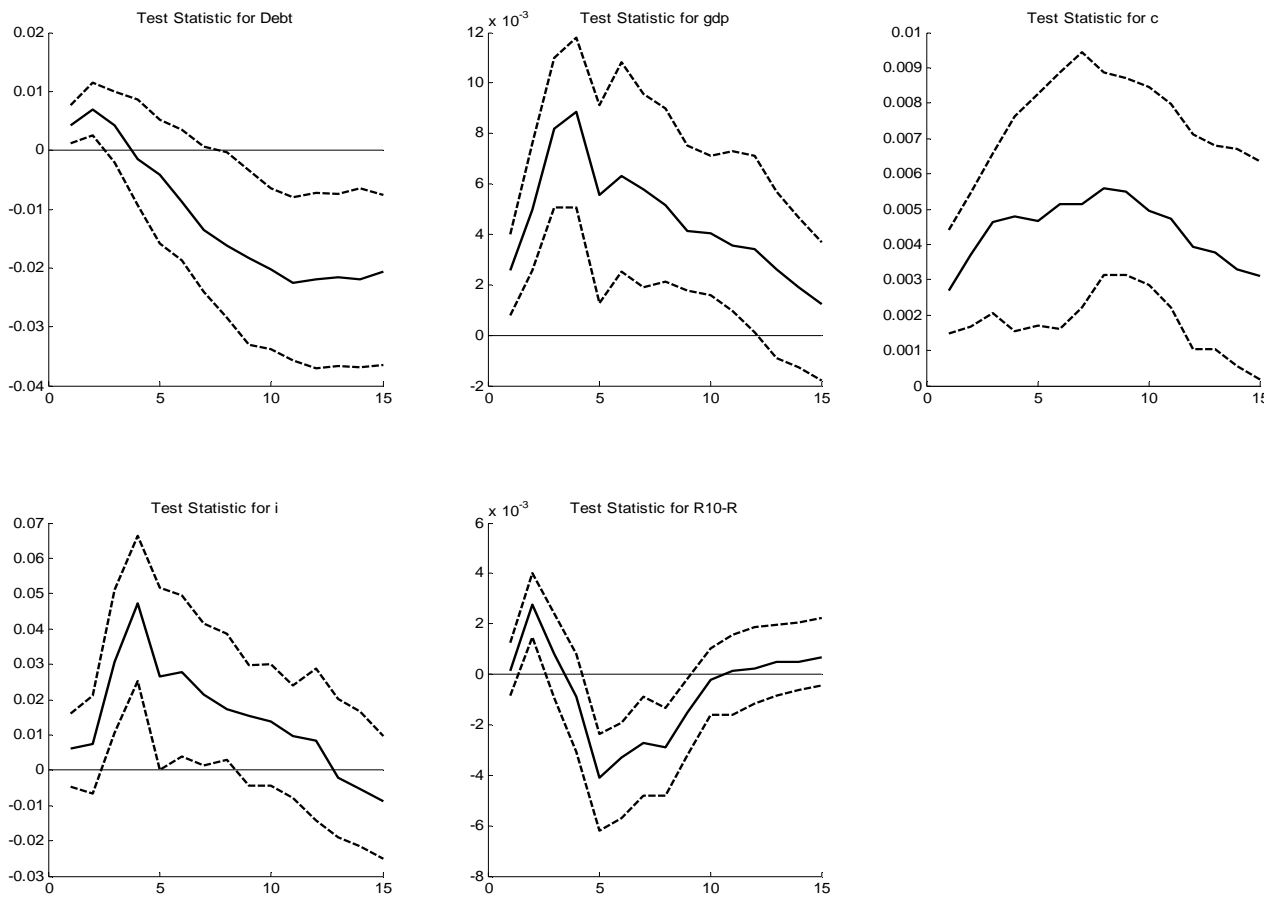

Figure 3a and $3 \mathbf{b}$ (slope of the yield curve): Figure 3a reports a comparison between the effects of shocks with and without expected spending reversals, when the VAR model includes also the slope of the yield curve $(R 10-R)$, computed as difference between the yield on the 10-years government bond and the yield on the 3 months Treasury bill. Figure $3 \mathrm{~b}$ reports the statistic constructed to test the difference between the impulse responses in the two cases. The two impulse responses are statistical different at the $68 \%$ level for a certain horizon if the confidence bands do not include the zero line at that horizon. 

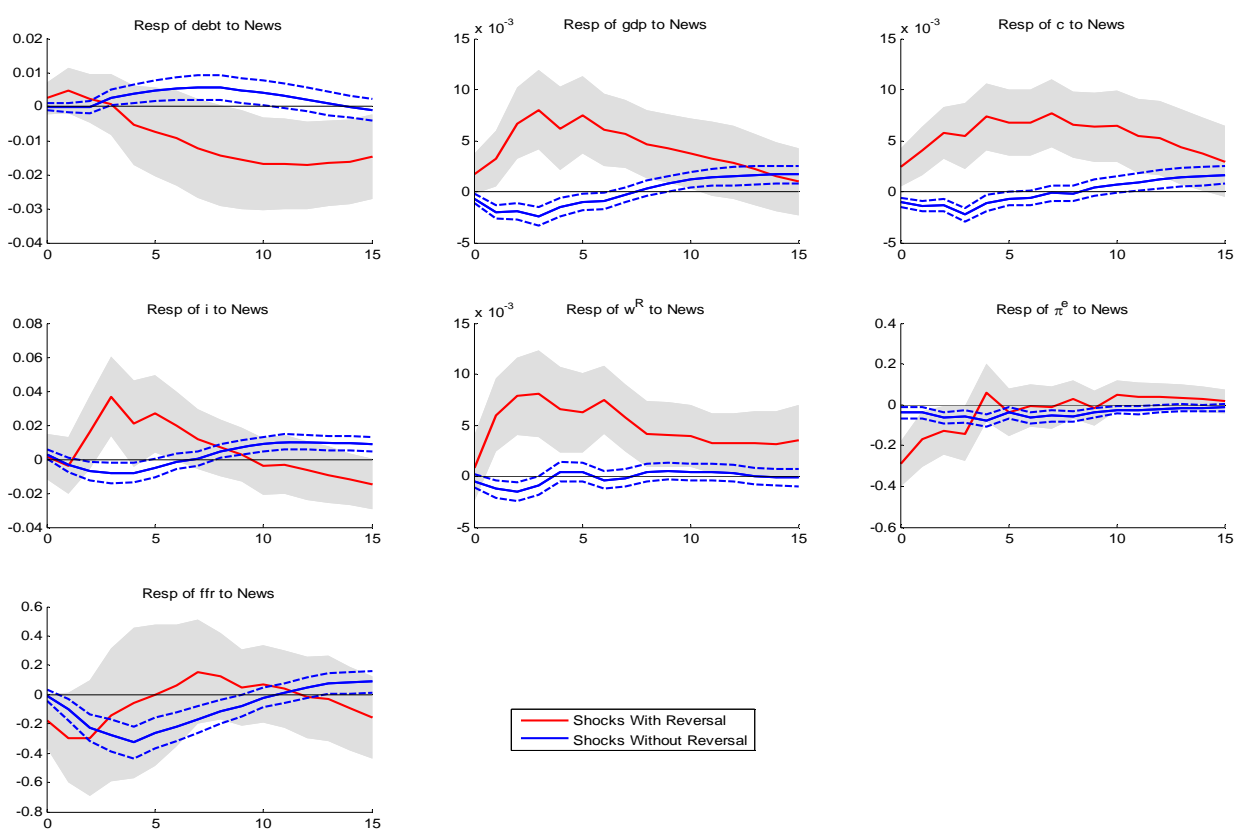

Testing the difference in the effects of the two shocks
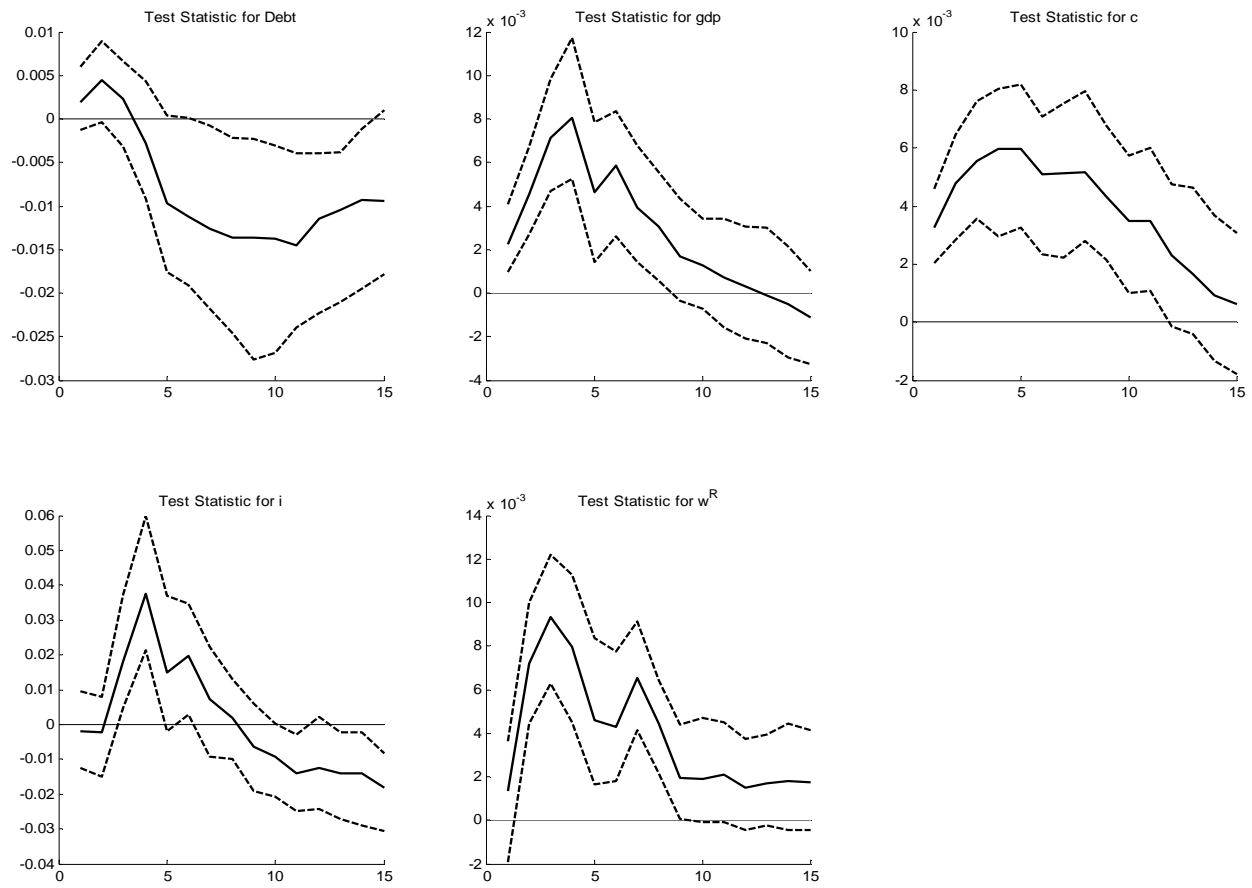

Figure 4a and 4b (real wages): Figure 4a reports a comparison between the effects of shocks with and without expected spending reversals, when the VAR model includes also real wages $\left(w^{R}\right)$. Figure $4 \mathrm{~b}$ reports the statistic constructed to test the difference between the impulse responses in the two cases. The two impulse responses are statistical different at the $68 \%$ level for a certain horizon if the confidence bands do not include the zero line at that horizon. 

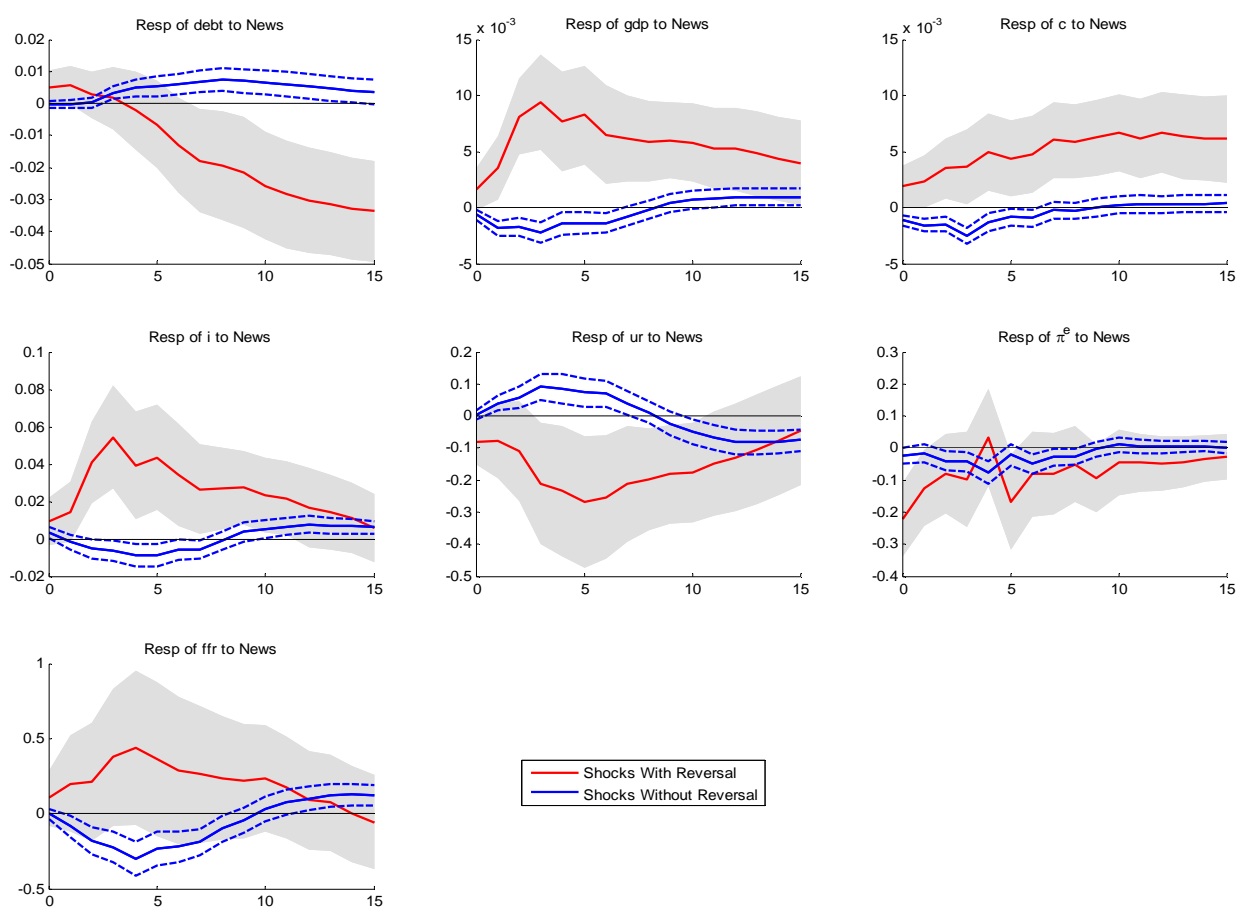

Shocks Without Reversal

5b)

Testing the difference in the effects of the two shocks
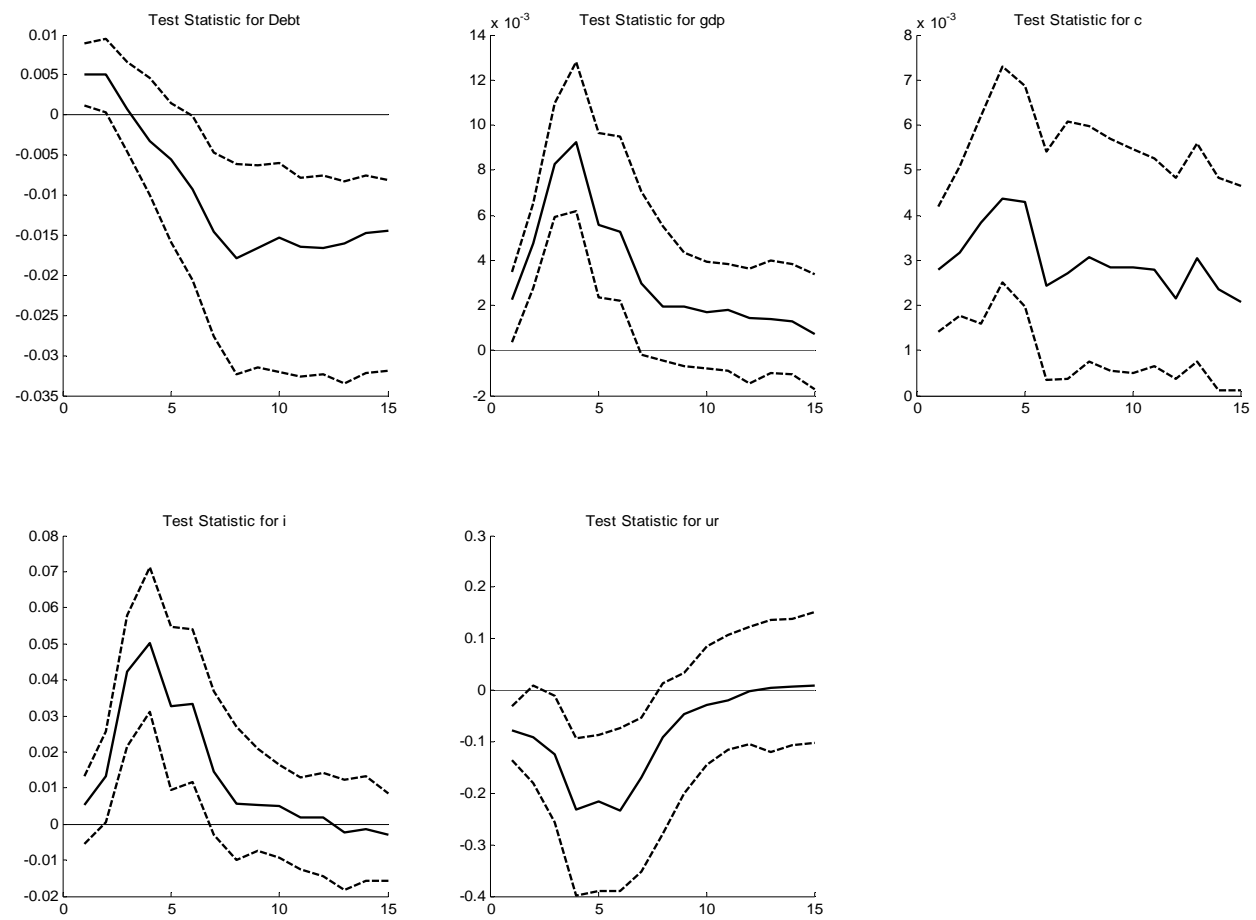

Figure 5a and 5b (unemployment rate): Figure 5a reports a comparison between shocks with and without expected spending reversals, when the VAR model includes also the unemployment rate (ur). Figure $5 \mathrm{~b}$ reports the statistic constructed to test the difference between the impulse responses in the two cases. The two impulse responses are statistical different at the $68 \%$ level for a certain horizon if the confidence bands do not include the zero line at that horizon. 

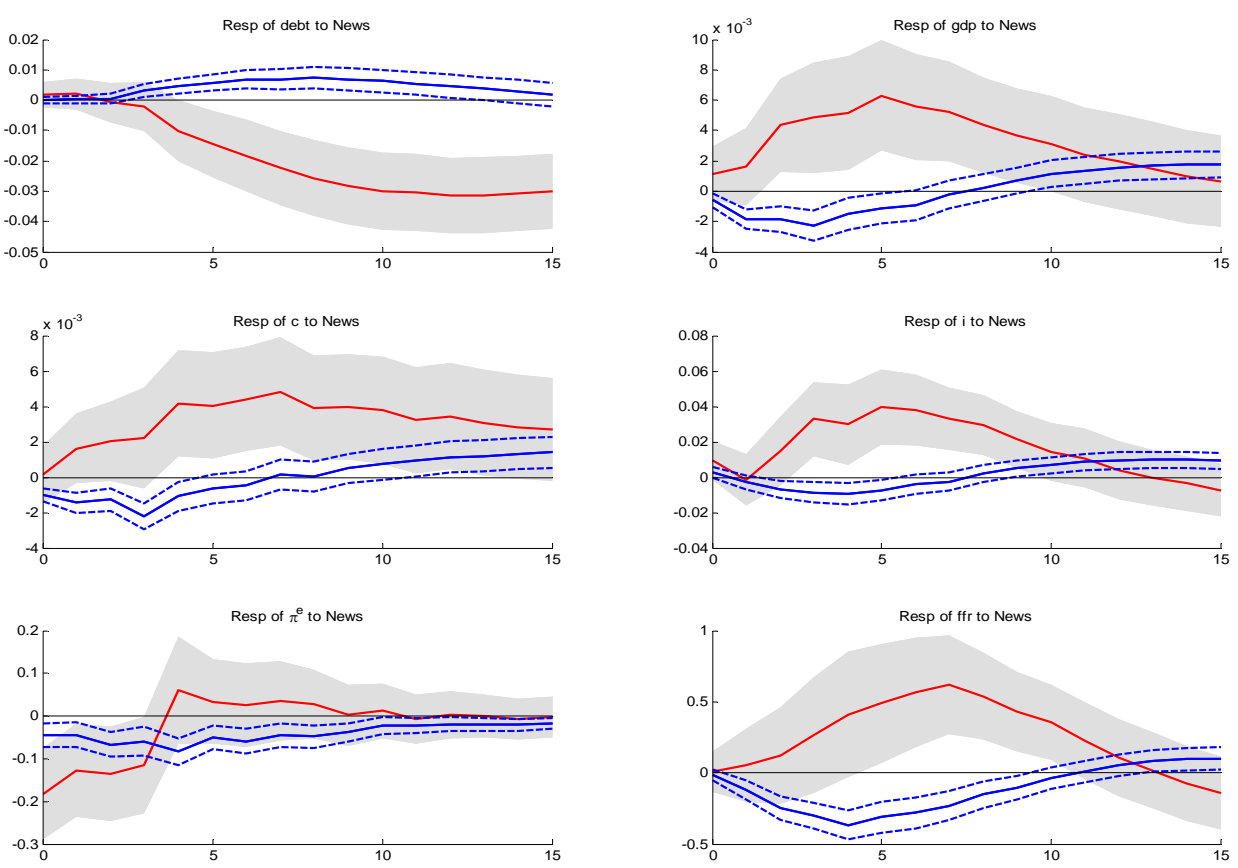

6b) Testing the difference in the effects of the two shocks
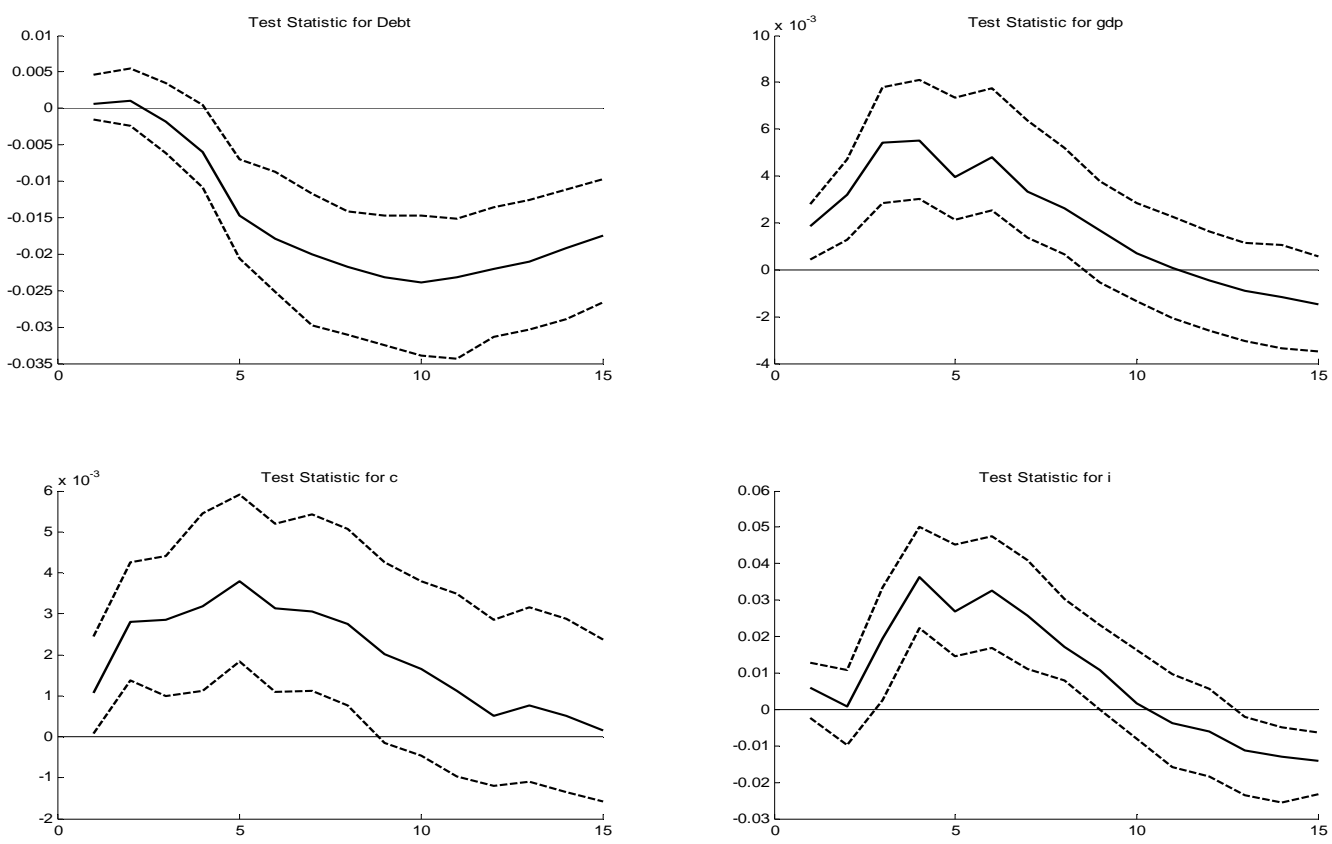

Figure 6a and 6b - 25-years interval: Figure 6a reports a comparison between shocks with and without expected spending reversals, when reversals are evaluated compared to a past interval of 25-years. Figure 6b reports the statistic constructed to test the difference between the impulse responses in the two cases. The two impulse responses are statistical different at the $68 \%$ level for a certain horizon if the confidence bands do not include the zero line at that horizon. 

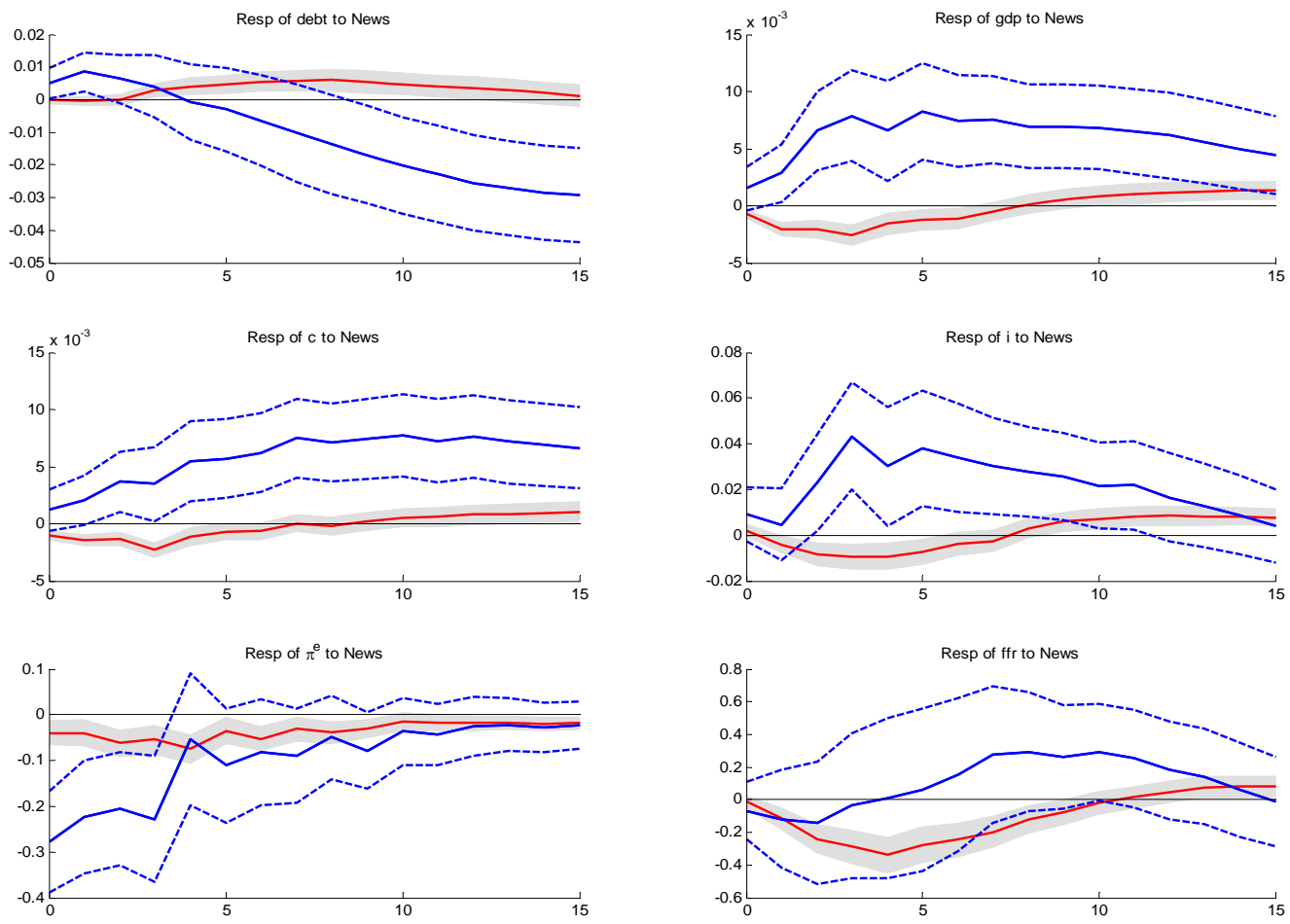

Shocks Without Revers

7b) Testing the difference in the effects of the two shocks
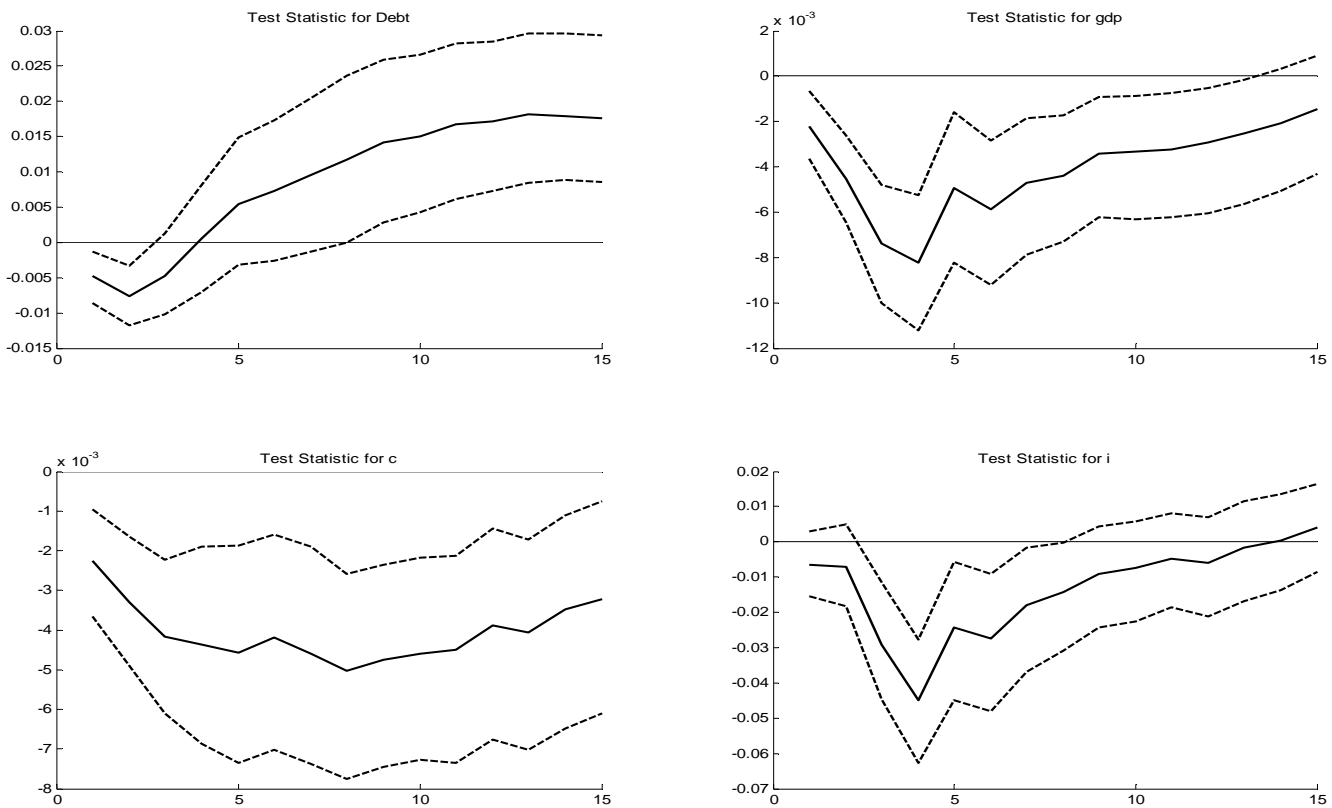

Figure $7 \mathbf{a}$ and $\mathbf{7 b}$ - inverting the ordering of shocks: In this exercise, the ordering of defense news shocks is inverted: first are shocks with no reversal, then the shocks with expected reversal. Figure 7a reports a comparison between shocks with and without expected spending reversals. Figure $7 \mathrm{~b}$ reports the statistic constructed to test the difference between the impulse responses in the two cases. The two sets of impulse responses are statistical different at the $68 \%$ level for a certain horizon if the confidence bands do not include the zero line at that horizon. 

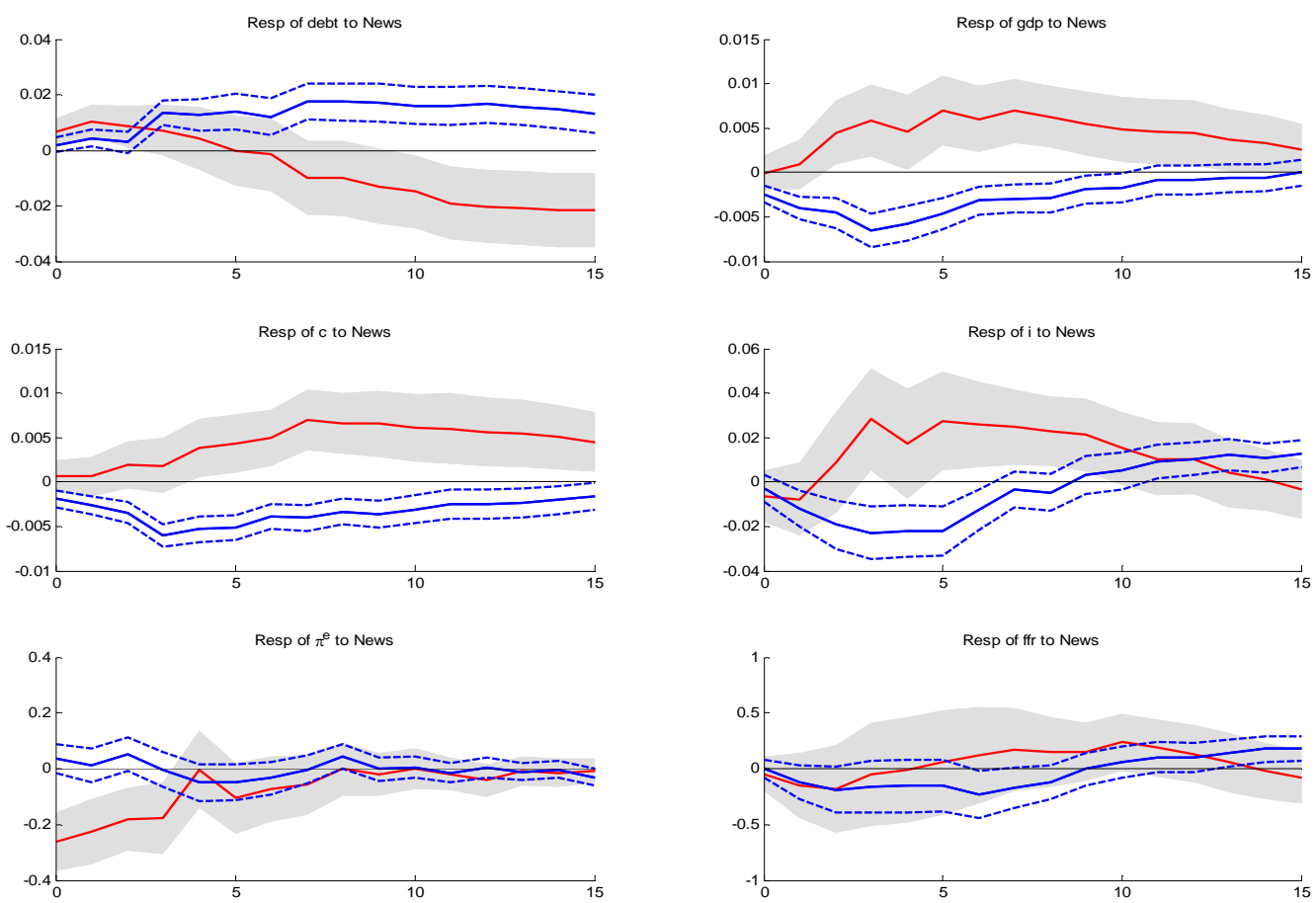
- Shocks With Reversal

8b) Testing the difference in the effects of the two shocks
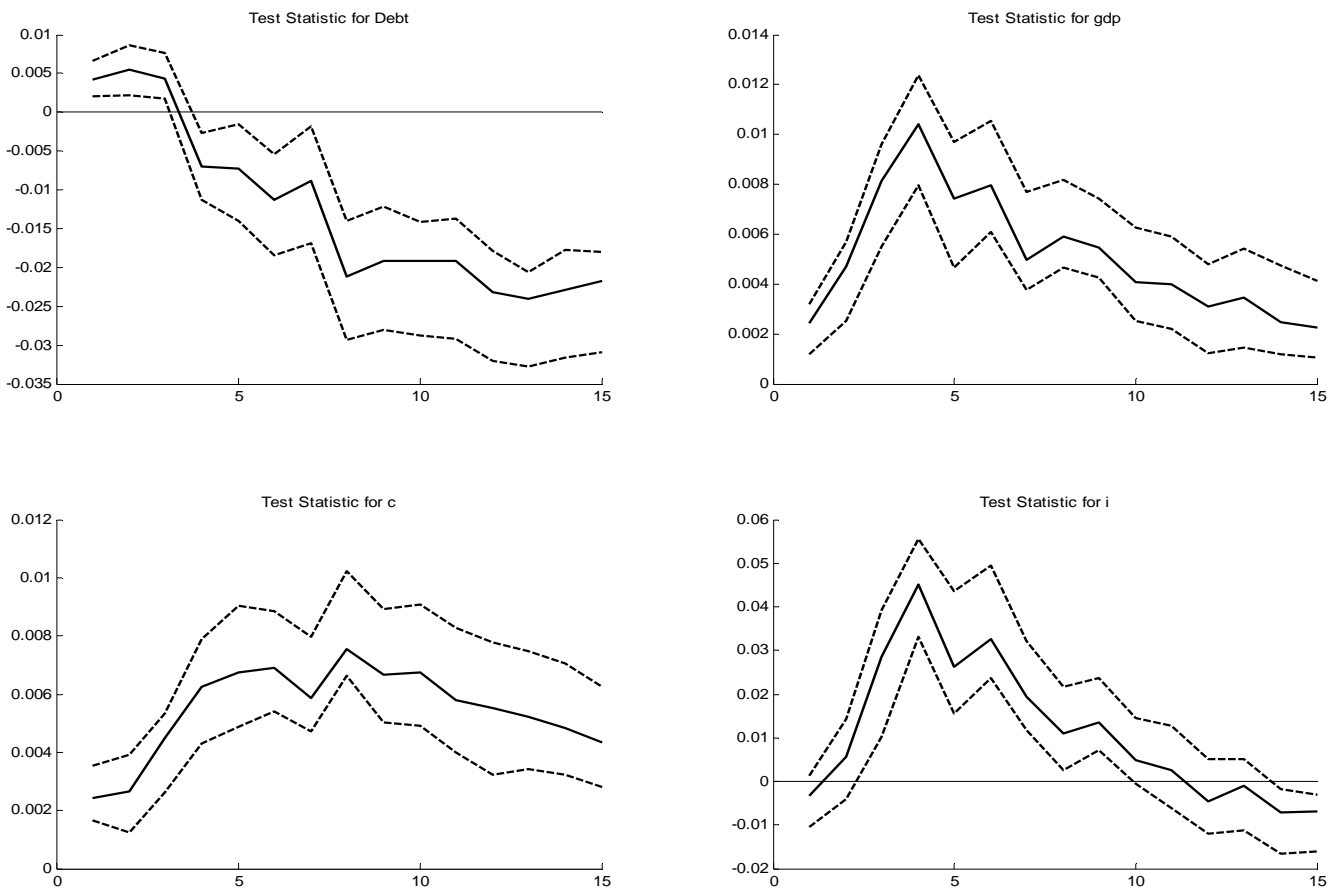

Figure 9a and 9b - Eliminating shocks that occur after the release of the forecasts: In this exercise, we estimate the baseline model excluding the four defense news shocks that take place after the release of the forecasts (see Appendix B). Figure 9a reports a comparison between shocks with and without expected spending reversals. Figure $9 \mathrm{~b}$ reports the statistic constructed to test the difference between the impulse responses in the two cases. The two sets of impulse responses are statistical different at the $68 \%$ level for a certain horizon if the confidence bands do not include the zero line at that horizon. 